\title{
ATTRIBUTE np CONTROL CHARTS USING RESAMPLING SYSTEMS FOR MONITORING NON-CONFORMING ITEMS UNDER EXPONENTIATED HALF-LOGISTIC DISTRIBUTION
}

\author{
AMMARA TANVEER ${ }^{1}$, MUHAMMAD AZAM ${ }^{2}$, MUHAMMAD ASLAM $^{3 *}$, \\ MUHAMMAD SHUJAAT NAWAZ ${ }^{4}$ \\ ${ }^{1}$ National College of Business Administration and Economics, Lahore 54660, Pakistan \\ ${ }^{2}$ Department of Statistics and Computer Science, University of Veterinary and Animal Sciences, \\ Lahore 54000, Pakistan \\ ${ }^{3}$ Department of Statistics, Faculty of Science, King Abdulaziz University, Jeddah 21551, Saudi Arabia \\ ${ }^{4}$ Higher Education Department, Government of the Punjab, Lahore 54000, Pakistan
}

An attribute $\mathrm{np}$ control chart has been designed using resampling systems for monitoring non-conforming items under exponentiated half-logistic distribution. We suppose that lifetime follows exponentiated half-logistic distribution. For the proposed control charts, the optimal parameters and control limits have been obtained. The operational formulas for in-control and out of control average run lengths $(A R L s)$ have been derived. Control constants are established by considering the target in-control $A R L$ at a normal process. The extensive $A R L$ tables are reported for various parameters and shifted values of process parameters. The performance of the proposed control chart is evaluated with several existing charts with regard to $A R L s$, which empower the presented chart and prove far better for timely detection of assignable causes. A wide range of tables, a real-life example, and simulation study for RGS and MDS are given for a better understanding of the problem.

Keywords: attribute chart, time truncation, process, statistical distributions, sampling schemes

\section{Introduction}

Quality is the main important feature for production growth and standing. Statistical techniques can be used to improve the quality of the product. The control chart is the

${ }^{*}$ Corresponding author, e-mail address: aslam_ravian@hotmail.com

Received 5 November 2019, accepted 18 August 2020 
primary instrument to monitor the process and to finally develop high-quality products. Control charts provide a fast signal when the process is out of control. The control chart enables to monitor the deviation of the method over time and discovers the foundation for differences. Amongst the two types of control charts, i.e., attribute control charts and variable control charts, the former is used to track the quality characteristic of an attribute. Examples of attribute control charts include $\mathrm{p}, \mathrm{np}$, and $\mathrm{u}$ control charts. The variable control charts, e.g., $\overline{\mathrm{X}}, \mathrm{R}$, and $\mathrm{S}$ control charts are used to monitor the characteristics of the issue in question. For the construction of control charts, different schemes, e.g., single sampling scheme, double sampling scheme, repetitive group sampling scheme, and multiple dependent state sampling (MDS) schemes are used.

Repetitive group sampling (RGS) scheme is introduced by Sherman [1]. RGS is the expansion of a single sampling scheme. The control chart under RGS has two pairs of control limits. If a point lies within the inner control limits, the procedure is said to be in-control, whereas if a point lies beyond the outer control limits, the process is out of control. The sampling is repeated if a point is identified between inner and outer control limits until a decision is made. Balamurali and Jun [2] introduce the RGS plan for variable inspection. They reveal that the average sample number (ASN) of the RGS plan is lesser than both single and double sampling plans. Ahmad et al. [3] Design the $\bar{X}$ control chart for RGS based on the process capability index. Aslam et al. [4], using RGS, present attributes and variables control charts. Aslam et al. [5] introduce a t-chart using RGS. Rao [6] introduces a control chart based on exponentiated half logistic distribution with known shape parameters. The wide range of tables based on a simulated study is given.

Multiple dependent state (MDS) sampling scheme was created by Wortham and Baker [7]. The conclusion will be made not only on current but also on a previous or upcoming lot. The plan parameters are established by meeting the vendor and customer hazards at a number of acceptable levels of quality and by restricting the amount of quality. Later, Aslam et al. [8] propose a new loss consideration process under multiple dependent state variable sampling plans. Aslam et al. [9] propose multiple dependent state control chart based on two pairs of control limits. The proposed control chart is compared with the existing $\overline{\mathrm{X}}$ chart which shows that the proposed control chart performs better than Shewart X bar control chart. Rao and Naidu [10] Recommend a fresh sampling plan for exponentiated half logistic distribution for group acceptance. The scheme implemented by them shows that the percentile ratio rises for all parameters and decreases the number of associations. Aslam [11] proposes a control chart by using the Weibull distribution based on MDS sampling which is more efficient than the existing control charts.

In this study, an attribute np control chart for process monitoring using exponentiated half logistic distribution (EHLD) is provided as based on RGS and MDS. Both of the control charts are compared with the existing control charts. 
RGS chart is compared with the existing chart on the basis of exponentiated half logistic distribution provided by Jeyadurga et al. [12]. We acquire optimal parameters, control limits, and also show the respective $A R L$ and $A S N$ values of the control chart using RGS. We compare the table values for the shape parameters $\alpha=2$ and 3 and the specified $A R L$ is $r_{0}=300$ and 370 , respectively. We can infer from our data the proposed chart identifies the process shift quicker than the existing chart under RGS sampling scheme. The control chart performance in RGS is also compared with the control chart presented by Rao [6] based on EHLD. Results are presented in form of tables using different shape and scale parameters, respectively.

The efficiency of the proposed MDS control chart is compared to the control chart results by Aslam [11]. We calculate the optimal parameters, control limits, and present the respective $A R L$ values of the control chart, using dependent state sampling. The results are shown in the form of a table which indicates that the proposed control chart is more responsive than the existing control chart to recognize a shift in the process. The efficiency of the proposed MDS control chart is also compared with the results of Rao [6] and concluded in the form of tables, using different $A R L_{0}(200,300,370, i=1,2,3)$.

Moreover, using RGS and MDS, we find the $A R L$ s when scale and shape parameters are shifted separately, and also when both parameters are shifted at once. A real-life data example is also used to demonstrate the proposed $\mathrm{np}$ control chart by using simulated data.

\section{The exponentiated half-logistic distribution (EHLD)}

EHLD is a simplification of half-logistic distribution proposed by Mudholkar and Srivastava [13]. Cordeiro et al. [14] study mathematical properties of the exponentiated half logistic family of distributions. Seo and Kang [15] derive moment estimators and maximum likelihood estimators of unknown parameters of exponentiated half logistic distribution along with an entropy. Elgarhy et al. [16] present exponentiated extended family of distributions along with its mathematical properties and applications. Usman et al. [17] study the Kumaraswamy half-logistic distribution and explore the properties and applications of the presented model. Anwar and Bibi [18] propose half logistic generalized Weibull (HLGW) distribution and investigate its properties.

The cumulative distribution function $(F(t)$ and the probability density function $(f(t)$ of EHLD are given as

$$
F(t)=\left(\frac{1-\mathrm{e}^{-t / \sigma}}{1+\mathrm{e}^{-t / \sigma}}\right)^{\alpha}, \quad t \geq 0, \alpha>0, \sigma>0
$$




$$
f(t)=\frac{2 \alpha \mathrm{e}^{-t / \sigma}\left(1-\mathrm{e}^{-t / \sigma}\right)^{\alpha-1}}{\sigma\left(1+\mathrm{e}^{-t / \sigma}\right)^{\alpha+1}}, t \geq 0, \alpha>0, \sigma>0
$$

Here $\alpha$ is the shape parameter, and $\sigma$ is the scale parameter. The arithmetic mean of EHLD distribution is specified as

$$
\mu=\sigma \ln \left(\frac{1+0.5^{1 / \alpha}}{1-0.5^{1 / \alpha}}\right), \quad \eta=\ln \left(\frac{1+0.5^{1 / \alpha}}{1-0.5^{1 / \alpha}}\right), \quad \mu=\sigma \eta, \quad \sigma=\frac{\mu}{\eta}
$$

\section{Design of the proposed control chart under RGS}

It is important to note that the attribute's RGS plan is a generalization of the ordinary single sampling plan. In RGS, the sampling is repeated until a decision is made. RGS is more efficient than the single sampling in terms of the ASN which is needed for deciding on the disposition of the lot.

Following are the steps of the np control chart based on the RGS scheme.

Step 1. From the manufacturing process, choose a subgroup as a random sample of size $n$ and place it on the life test for the particular time $t_{0}$. Count number of failures says $D$ during $t_{0}$.

Step 2. If $L C L_{1} \leq D \leq U C L_{1}$, then the process is said to be in control. If either $D \geq U C L_{2}$, or $D \leq L C L_{2}$, then the process is said to be out of control.

Step 3. Repeat Steps 1 and 2 if $L C L_{2}<D<L C L_{1}$ or $U C L_{1}<D<U C L_{2}$, until a decision is made.

The control limits for an $\mathrm{np}$ control chart are as follows:

$$
\begin{gathered}
U C L_{1}=n p_{0}+k_{1} \sqrt{n p_{0}\left(1-p_{0}\right)} \\
L C L_{1}=\max \left(0, n p_{0}-k_{1} \sqrt{n p_{0}\left(1-p_{0}\right)}\right) \\
U C L_{2}=n p_{0}+k_{2} \sqrt{n p_{0}\left(1-p_{0}\right)} \\
L C L_{2}=\max \left(0, n p_{0}-k_{2} \sqrt{n p_{0}\left(1-p_{0}\right)}\right)
\end{gathered}
$$

The likelihood $p_{0}$ is generally unknown. So, the control limits to be used in practical applications will be as given by [19]: 


$$
\begin{gathered}
U C L_{1}=\bar{d}+k_{1} \sqrt{\bar{d}\left(1-\frac{\bar{d}}{n}\right)} \\
L C L_{1}=\max \left(0, \bar{d}-k_{1} \sqrt{\bar{d}\left(1-\frac{\bar{d}}{n}\right)}\right) \\
U C L_{2}=\bar{d}+k_{2} \sqrt{\bar{d}\left(1-\frac{\bar{d}}{n}\right)} \\
L C L_{2}=\max \left(0, \bar{d}-k_{2} \sqrt{\bar{d}\left(1-\frac{\bar{d}}{n}\right)}\right)
\end{gathered}
$$

where $\bar{d}$ is the average number of failures in a subgroup over a preliminary sample. However, in this paper, we will consider the control limits in the form of equation (4) to investigate the performance of the proposed chart analytically in terms of the average run length.

The method is stated to be controlled if $t=\alpha \mu_{0}, \mu=\mu_{0}$ (scale parameter is $\sigma=\sigma_{0}$ and shape parameter is $\alpha=\alpha_{0}$ ). If the process is in control, the failure likelihood $p_{0}$ is given by equation (1)

$$
\begin{aligned}
p & =\left(\frac{1-\mathrm{e}^{-t / \sigma}}{1+\mathrm{e}^{-t / \sigma}}\right)^{\alpha}, \quad p_{0}=\left(\frac{1-\mathrm{e}^{-a \mu_{0} / \sigma_{0}}}{1+\mathrm{e}^{-a \mu_{0} / \sigma_{0}}}\right)^{\alpha_{0}} \\
& =\left(\frac{1-\mathrm{e}^{-a \sigma_{0} \eta_{0} / \sigma_{0}}}{1+\mathrm{e}^{-a \sigma_{0} \eta_{0} / \sigma_{0}}}\right)^{\alpha_{0}}=\left(\frac{1-\mathrm{e}^{-a \eta_{0}}}{1+\mathrm{e}^{-a \eta_{0}}}\right)^{\alpha_{0}}
\end{aligned}
$$

\subsection{Shift in the scale parameter}

We suppose that the scale parameter is shifted from $\sigma_{0}$ to $\sigma_{1}=c \sigma_{0}$, where $c$ is a shift constant (or scale parameter is $\sigma=\sigma_{1}$ ). So, if the process is out of control, the failure likelihood of an item $p_{1}$ is specified as 


$$
\begin{aligned}
p & =\left(\frac{1-\mathrm{e}^{-t / \sigma}}{1+\mathrm{e}^{-t / \sigma}}\right)^{\alpha}, \quad p_{1}=\left(\frac{1-\mathrm{e}^{-\alpha \mu_{0} / \sigma_{1}}}{1+\mathrm{e}^{-\alpha \mu_{0} / \sigma_{1}}}\right)^{\alpha} \\
& =\left(\frac{1-\mathrm{e}^{-a \sigma_{0} \eta_{0} / c \sigma_{0}}}{1+\mathrm{e}^{-a \sigma_{0} \eta_{0} / c \sigma_{0}}}\right)^{\alpha}=\left(\frac{1-\mathrm{e}^{-a \eta_{0} / c}}{1+\mathrm{e}^{-a \eta_{0} / c}}\right)^{\alpha}
\end{aligned}
$$

\subsection{Shift in shape and both shape and scale parameters}

If shape parameter is shifted from $\alpha_{0}$ to $\alpha_{1}=f \alpha_{0}$ (or the shape parameter is $\alpha=\alpha_{1}$ ). The probability that an item is failed $p_{2}$ is specified as

$$
p_{2}=\left(\frac{1-\mathrm{e}^{-a \eta_{1}}}{1+\mathrm{e}^{-a \eta_{1}}}\right)^{f \alpha_{0}} \quad \text { where } \quad \eta_{1}=\ln \left(\frac{1+0.5^{1 / f \alpha_{0}}}{1-0.5^{1 / f \alpha_{0}}}\right)
$$

Suppose that both the shape and scale parameters are shifted to $\alpha_{1}=f a_{0}$ and $\sigma_{1}=c \sigma_{0}$ (now the shape parameter is $\alpha_{1}$ and the scale parameter is $\sigma_{1}$ ). The likelihood that an item is failed $p_{3}$ is specified as

$$
p_{3}=\left(\frac{1-\mathrm{e}^{-a \eta_{1} / c}}{1+\mathrm{e}^{-a \eta_{1} / c}}\right)^{f a_{0}} \quad \text { where } \quad \eta_{1}=\ln \left(\frac{1+0.5^{1 / f \alpha_{0}}}{1-0.5^{1 / f \alpha_{0}}}\right)
$$

When the probability that the process is likely to be in-control, $L_{1}(p)$ is specified as

$$
\begin{aligned}
& L_{1}(p)=P\left(L C L_{1} \leq d \leq U C L_{1}\right), \quad d=0,1,2, \ldots, n \\
& L_{1}(p)=\sum_{d=\left[L C L_{1}\right]+1}^{\left[U C L_{1}\right]}\left(\begin{array}{l}
n \\
d
\end{array}\right) p^{d}(1-p)^{n-d}, \quad d=0,1,2, \ldots, n
\end{aligned}
$$

Similarly, when the process is likely to be stated out of control, $L_{2}(p)$ is specified as

$$
\begin{aligned}
& L_{2}(p)=P\left(d>U C L_{2}\right)+P\left(d<L C L_{2}\right) \\
& L_{2}(p)=\sum_{d=\left[U C L_{2}\right]+1}^{\left[L C L_{2}\right]}\left(\begin{array}{l}
n \\
d
\end{array}\right) p^{d}(1-p)^{n-d}
\end{aligned}
$$
trated

The likelihood of repeating the sampling until the choice is made, $L_{3}(p)$ is as illus-

$$
\begin{aligned}
& L_{3}(p)=P\left(L C L_{2} \leq d<L C L_{1}\right)+P\left(U C L_{1} \leq d<U C L_{2}\right) \\
& L_{3}(p)=\sum_{d=\left[L C L_{2}\right]+1}^{\left[L C L_{1}\right]}\left(\begin{array}{l}
n \\
d
\end{array}\right) p^{d}(1-p)^{n-d}+\sum_{d=\left[U C L_{1}\right]+1}^{\left[U C L_{2}\right]}\left(\begin{array}{l}
n \\
d
\end{array}\right) p^{d}(1-p)^{n-d}
\end{aligned}
$$


The likelihood that the process will be controlled the ASN and average run length (ARL) using RGS are given below:

$$
\begin{gathered}
p_{\text {in }}(p)=\frac{L_{1}(p)}{L_{3}-(p)} \\
A S N(p)=\frac{n}{1-L_{3}(p)} \\
A R L=\frac{1}{1-p_{\text {in }}(p)}
\end{gathered}
$$

The likelihood that the process will be controlled when it is under control using RGS, the scale parameter is shifted, shape parameter is shifted and both shape and scale parameters are shifted is given in equations (13a)-(13d), respectively:

$$
\begin{aligned}
& p_{\text {in }}\left(p_{0}\right)=\frac{L_{1}\left(p_{0}\right)}{1-L_{3}\left(p_{0}\right)} \\
& p_{\text {in }}\left(p_{1}\right)=\frac{L_{1}\left(p_{1}\right)}{1-L_{3}\left(p_{1}\right)} \\
& p_{\text {in }}\left(p_{2}\right)=\frac{L_{1}\left(p_{2}\right)}{1-L_{3}\left(p_{2}\right)} \\
& p_{\text {in }}\left(p_{3}\right)=\frac{L_{1}\left(p_{3}\right)}{1-L_{3}\left(p_{3}\right)}
\end{aligned}
$$

The $A S N$ for the proposed chart when the process is in control, the scale parameter is shifted, the shape parameter is shifted and both scale and shape parameters are shifted is given in equation (14a)-(14d), respectively:

$$
\begin{aligned}
& \operatorname{ASN}\left(p_{0}\right)=\frac{n}{1-L_{3}\left(p_{0}\right)} \\
& \operatorname{ASN}\left(p_{1}\right)=\frac{n}{1-L_{3}\left(p_{1}\right)} \\
& \operatorname{ASN}\left(p_{2}\right)=\frac{n}{1-L_{3}\left(p_{2}\right)}
\end{aligned}
$$




$$
\operatorname{ASN}\left(p_{3}\right)=\frac{n}{1-L_{3}\left(p_{3}\right)}
$$

The $A R L$ for the proposed chart when the process is in control, the scale parameter is shifted, the shape parameter is shifted and both scale and shape parameters are shifted is given in equation (15a)-(15d), respectively:

$$
\begin{aligned}
& A R L_{0}=\frac{1}{1-p_{\text {in }}\left(p_{0}\right)} \\
& A R L_{1}=\frac{1}{1-p_{\text {in }}\left(p_{1}\right)} \\
& A R L_{2}=\frac{1}{1-p_{\text {in }}\left(p_{2}\right)} \\
& A R L_{3}=\frac{1}{1-p_{\text {in }}\left(p_{3}\right)}
\end{aligned}
$$

\subsection{Optimization conditions}

The following are the optimization conditions:

$\operatorname{Minimize} \operatorname{ASN}\left(p_{0}\right)$

Subject to

$$
\begin{aligned}
& A R L_{0} \geq r_{0} \\
& k_{2}>k_{1}
\end{aligned}
$$

\section{Algorithm}

Step 1. Set the values of $\alpha_{0}$ (shape parameter), $a$ (test termination ratio), $r_{0}$ (in-control target $A R L$ ), and set a greatest value for $A S N$ as $A S N_{m}$.

Step 2. Set the values of $n, k_{1}$ and $k_{2}$.

Step 3. Put the values of $a, \alpha_{0}$ in equation (6) to find the failure probability $\left(p_{0}\right)$.

Step 4. Discover the control limits of the proposed control chart using the values of $n, p_{0}, k_{1}$, and $k_{2}$ in equations (4a)-(4d).

Step 5. Find the likelihood that the process will be declared in-control when the process is in-control by replacing the values of $p_{0}$ and control limits in equations (10), (12), and (13a); also use the equation (15a) to locate $A R L_{0}$. By using equation (14a), compute the $A S N$ at $p_{0}$. 
Step 6. Check parameters $n, k_{1}$ and $k_{2}$ such that the in-control $A R L_{0}$ is as near as to the final value $r_{0}$. Make the comparison of $A S N\left(p_{0}\right)$ value with $A S N_{m}$. If $A S N\left(p_{0}\right) \leq A S N_{m}$, then set $A S N_{m}=A S N\left(p_{0}\right)$.

Step 7. Continue Steps 4-6 for various combinations of $n, k_{1}$ and $k_{2}$ until you get an $A R L_{0}$ as near as to $r_{0}$ and obtain the least value of $A S N$ as $A S N_{m}$.

Step 8. Replace the values $n, k_{1}$ and $k_{2}$ in equations (7)-(9), (13b)-(13d), (15b)-(15d) for discovering the out of control $A R L_{1}$ for various shift values. Use equations (14b)-(14d) to discover the respective $A S N S$.

\subsection{Control charts performance comparison}

Results are simulated using the proposed control chart and algorithm and are presented in tables. Tables A1-A5 present optimal parameters such as control coefficients $k_{2}$ and $k_{1}$ for fixed sample size $(n)$. These parameters are calculated to get $A R L$ value as close as the specified in-control $A R L=200,300$, and 370. Shape parameter $\alpha=1.5$, 2.0, 2.5, 3.0, shift constant $f$ from 1.0 to 0.1 , and sample sizes $n=10,15,20,25$ are chosen. It is found that $A R L$ and $A S N$ are decreasing if the shift constant is decreasing.

Tables A6-A8 present the optimal parameters for the shift in scale parameter, using shift $c$ from 1.0 to 0.1 .

Table A9 gives the optimal parameters for the shift in both shape and scale parameters for $\alpha=1.5,2.0,2.5$, and 3.0, using shift $c$ and $f$ from 1.0 to 0.1 .

In this segment, the control chart performance in RGS is contrasted with the available control chart presented by Jeyadurga et al. [12] as based on EHLD. Tables A10 and A11 demonstrate the optimum parameters $n, a, k_{1}, k_{2}$, higher and lower control boundaries along with $A R L$ and $A S N$ values, using RGS scheme for the shape parameter $\alpha=2$ and 3 and specified $r_{0}=300$ and 370 . These tables show that the proposed chart identifies the change quicker than the existing one. For example, when $r_{0}=300, \alpha=2$ and $n=25$, the proposed control chart identifies the shift at 41th observation and $A S N=29.64$. However, the shift is identified by the existing control chart at 116th observation.

The control chart performance in RGS is also contrasted with another available control chart presented by Rao [6] as based on EHLD. Tables A12 and A13 demonstrate the optimum parameters, higher and lower control boundaries, $A R L$ values using RGS scheme, and single sampling scheme for shape parameter $\alpha=2$ and $r_{0}=370$, and for the scale parameter $\alpha=2.5,3$, and $r_{0}=370$. The proposed control chart identifies the change quicker than the existing one. For example, when $r_{0}=370, \alpha=2$ and $n=25$, the proposed chart identifies the shift at 63 rd observation. However, the shift is identified by the existing control chart at 247 th observation. The shift in scale parameter is also shifted earlier, using the proposed control chart. 


\subsection{Illustrative example}

We consider Hinkley's [20] real dataset. This dataset for Saint Paul, Minneapolis, is 30 consecutive rainfall values (in inches) in March over a period of 30 years. The observed values are: $0.77,1.74,0.81,1.20,1.95,1.20,0.47,1.43,3.37,2.20,3.00,3.09$, $1.51,2.10,0.52,1.62,1.31,0.32,0.59,0.81,2.81,1.87,1.18,1.35,4.75,2.48,0.96$, $1.89,0.90,2.05$.

Seo et al. [21], Azimi and Sarikhanbaglu [22], Torabi and Bagheri [23], Seo and Kang [15], and others evaluated this dataset. The exponentiated half logistic distribution suits the information well, see Seo and Kang [15]. Here, $n=15, \alpha=2, a=0.77$, and $r_{0}=200$. The value of $p_{0}$ from equation (6) becomes 0.35 . The value of $\mu$ from equation (3) is calculated as 1.7627 with test duration $t_{0}=a \mu_{0}=0.77 \times 1.7627=1.3572$. The control limits under RGS are calculated as $U C L_{1}=2.52, U C L_{2}=2.79, L C L_{1}=0.8, L C L_{2}=0.57$ for the parameters $k_{1}=0.69, k_{2}=0.92$.

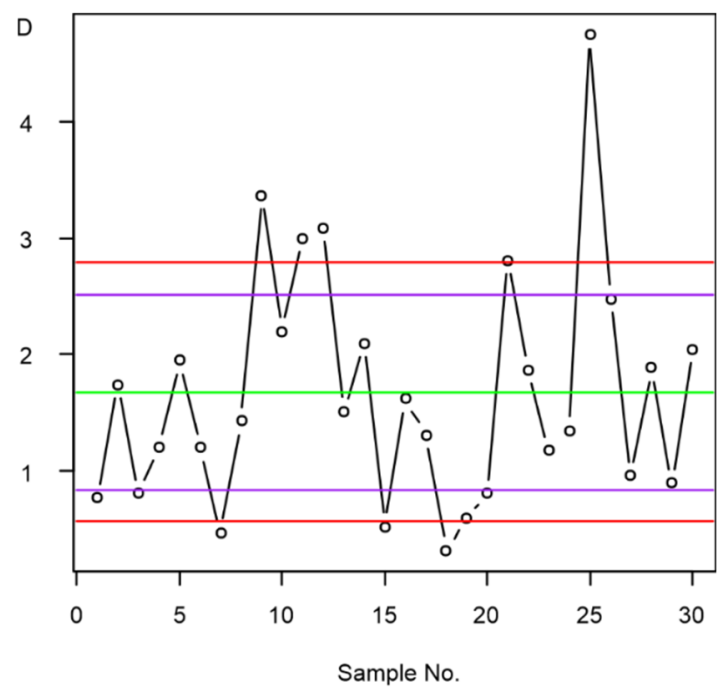

Fig. 1. Proposed RGS control chart for a real dataset

It can be seen from Fig. 1. That out of control signal is generated seven times while some points fall in the repetitive region.

\subsection{Simulation study}

Using simulated information, we address the implementation of the proposed control chart. The data is produced from an exponential half logistic distribution when 
$\alpha=3$ and $\sigma=1$. Let $n=25, a=0.76$, and $r_{0}=370$. The process is declared to be incontrol when $\alpha=3$ and $\sigma=1$. The value of $p_{0}$ from equation (6) is calculated as $0.3082, \mu=2.16$, the test duration is therefore calculated as $t_{0}=a \mu_{0}=0.76 \times 2.16$ $=1.64$. The value of $\bar{d}=\sum d_{i} / l=6.6$ and $l=20$. We find out the control limits coefficients $k_{1}=1.06173089$ and $k_{2}=1.131890$ and control limits are $U C L_{1}=8.94, U C L_{2}$ $=9.09, L C L_{1}=4.25, L C L_{2}=4.10$, the amount of failures per subgroup is reported before the specified time.

Table 1. The simulated data

\begin{tabular}{|c|c|c|c|c|c|c|c|c|c|c|}
\hline Subgroup & 1 & 2 & 3 & 4 & 5 & 6 & 7 & 8 & 9 & 10 \\
\hline$D$ & 7 & 8 & 6 & 7 & 8 & 6 & 8 & 3 & 5 & 7 \\
\hline Subgroup & 11 & 12 & 13 & 14 & 15 & 16 & 17 & 18 & 19 & 20 \\
\hline$D$ & 8 & 6 & 7 & 6 & 8 & 8 & 5 & 6 & 5 & 8 \\
\hline
\end{tabular}

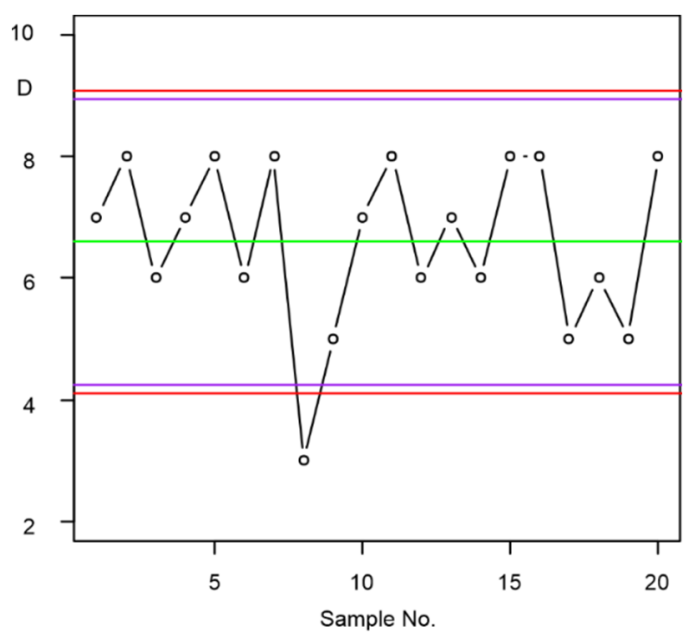

Fig. 2. The proposed RGS control chart for simulated data.

We can see from Fig. 2 that if the number of fail items in the subgroup is 5, 6, 7, or 8 , the process is said to be in-control. The sampling will be repeated if the subgroup includes 9 failed items. If the number of failures is less than or equal to 4 , the process is said to be out of control.

\section{Design of the proposed control chart under MDS}

Under the MDS scheme, the decision about the in-control or the out of control process is made, considering the results of the previous samples. If we select a sample from 
the online process and post it on the control chart, then it may fall in any of three mutually exclusive states, i.e., in-control state, out of control state, or in the state in which the decision depends on the previous samples. Following are the steps of np control chart based on the MDS scheme.

Step 1. Choose from the production process a random sample of size $n$. Count failed items $\mathrm{D}$ for a specified time $t=a \mu_{0}$, where $\mu_{0}$ is the target mean when the process is incontrol and $a$ is constant.

Step 2. If $L C L_{2} \leq D \leq U C L_{2}$, declare the process as in-control. If $D>U C L_{1}$ or $D<L C L_{1}$, declare the process as out of control. For all the other cases, repeat the process until $i$ th sample and declare the process as in-control if $L C L_{2} \leq D \leq U C L_{2}$ for all $i$ samples.

The method is stated to be controlled when $t=a \mu_{0}, \mu=\mu_{0}$. We express the scale parameter $\sigma$ in terms of $\mu$ using equation (3b), and then equation (1) can be rewritten as

$$
p_{0}=\left(\frac{1-\mathrm{e}^{-a \eta}}{1+\mathrm{e}^{-a \eta}}\right)^{\alpha}
$$

\subsection{Shift in scale and shape parameters}

We are designing a chart for monitoring mean shift. Assume that the process mean is shifted from $\mu=\mu_{0}$ and $\mu_{1}=c \mu_{0}$, then equation (1) becomes

$$
p_{1}=\left(\frac{1-\mathrm{e}^{-a \eta / c}}{1+\mathrm{e}^{-a \eta / c}}\right)^{\alpha}
$$

If the shape parameter is shifted from $\alpha_{0}$ to $\alpha_{1}=f \alpha_{0}$ (or the shape parameter is $\alpha=\alpha_{1}$ ), then equation (1) becomes

$$
p_{2}=\left(\frac{1-\mathrm{e}^{-a \eta_{1}}}{1+\mathrm{e}^{-a \eta_{1}}}\right)^{f \alpha_{0}} \quad \text { where } \quad \eta_{1}=\ln \frac{1+0.5^{1 / f \alpha_{0}}}{1-0.5^{1 / f \alpha_{0}}}
$$

\subsection{Shift in both shape and scale parameters}

Suppose that the shape and scale of both parameters are shifted to $\alpha_{1}=f \alpha_{0}$ and $\sigma_{1}=c \sigma_{0}$ (now the shape parameter is $\alpha_{1}$ and the scale parameter is $\sigma_{1}$ ). The likelihood that an item is failed $p_{3}$ is specified as 


$$
p_{3}=\left(\frac{1-\mathrm{e}^{-a \eta_{1} / c}}{1+\mathrm{e}^{-a \eta_{1} / c}}\right)^{f \alpha_{0}} \quad \text { where } \quad \eta_{1}=\ln \frac{1+0.5^{1 / f \alpha_{0}}}{1-0.5^{1 / f \alpha_{0}}}
$$

The probability that the process is stated in-control if the process is in-control is

$$
\begin{aligned}
& P_{\text {in }}=P\left(L C L_{2} \leq D \leq U C L_{2}\right)+\left(P\left(L C L_{1} \leq D \leq L C L_{2}\right)\right. \\
& \left.+P\left(U C L_{2} \leq D \leq U C L_{1}\right)\right) \times\left(P\left(L C L_{2} \leq D \leq U C L_{2}\right)\right)^{i} \\
& \frac{P_{i n}^{0}}{p_{0}}=P\left(d \geq L C L_{2}\right)+P\left(d \leq U C L_{2}\right)+\left(P\left(d \geq L C L_{1}\right)+P\left(d \leq L C L_{2}\right)\right. \\
& \left.+P\left(d \geq U C L_{2}\right)+P\left(d \leq U C L_{1}\right)\right) \times\left(P\left(d \geq L C L_{2}\right)+P\left(d \leq U C L_{2}\right)\right)^{i} \\
& \frac{P_{i n}^{0}}{p_{0}}=\sum_{d=\left[L C L_{2}\right]+1}^{n}\left(\begin{array}{l}
n \\
d
\end{array}\right) p_{0}^{d}\left(1-p_{0}\right)^{n-d}+\sum_{d=0}^{\left[U C L_{2}\right]}\left(\begin{array}{l}
n \\
d
\end{array}\right) p_{0}^{d}\left(1-p_{0}\right)^{n-d} \\
& +\left[\sum_{d=\left[L C L_{1}\right]+1}^{n}\left(\begin{array}{l}
n \\
d
\end{array}\right) p_{0}^{d}\left(1-p_{0}\right)^{n-d}+\sum_{d=0}^{\left[L C L_{2}\right]}\left(\begin{array}{l}
n \\
d
\end{array}\right) p_{0}^{d}\left(1-p_{0}\right)^{n-d}\right. \\
& \left.+\sum_{d=\left[U C L_{2}\right]+1}^{n}\left(\begin{array}{l}
n \\
d
\end{array}\right) p_{0}^{d}\left(1-p_{0}\right)^{n-d}+\sum_{d=0}^{\left[U C L_{1}\right]}\left(\begin{array}{l}
n \\
d
\end{array}\right) p_{0}^{d}\left(1-p_{0}\right)^{n-d}\right] \\
& \times\left[\sum_{d=\left[L C L_{2}\right]+1}^{n}\left(\begin{array}{l}
n \\
d
\end{array}\right) p_{0}^{d}\left(1-p_{0}\right)^{n-d}+\sum_{d=0}^{\left[U C L_{2}\right]}\left(\begin{array}{l}
n \\
d
\end{array}\right) p_{0}^{d}\left(1-p_{0}\right)^{n-d}\right]^{i} \\
& \frac{P_{i n}^{0}}{p_{0}}=\sum_{d=\left[L C L_{2}\right]+1}^{\left[U C L_{2}\right]}\left(\begin{array}{l}
n \\
d
\end{array}\right) p_{0}^{d}\left(1-p_{0}\right)^{n-d} \\
& +\left[\sum_{d=\left[L C L_{1}\right]+1}^{\left[L C L_{2}\right]}\left(\begin{array}{l}
n \\
d
\end{array}\right) p_{0}^{d}\left(1-p_{0}\right)^{n-d}+\sum_{d=\left[U C L_{2}\right]+1}^{\left[U C L_{1}\right]}\left(\begin{array}{l}
n \\
d
\end{array}\right) p_{0}^{d}\left(1-p_{0}\right)^{n-d}\right] \\
& \times\left[\sum_{d=\left[L C L_{2}\right]+1}^{\left[U C L_{2}\right]}\left(\begin{array}{l}
n \\
d
\end{array}\right) p_{0}^{d}\left(1-p_{0}\right)^{n-d}\right]^{i}
\end{aligned}
$$

Likewise, the probability that the process will be stated in-control when the process is shifted to $\mu_{1}$ is specified as 


$$
\begin{aligned}
\frac{P_{i n}^{1}}{p_{1}}= & \sum_{d=\left[L C L_{2}\right]+1}^{\left[U C L_{2}\right]}\left(\begin{array}{l}
n \\
d
\end{array}\right) p_{1}^{d}\left(1-p_{1}\right)^{n-d} \\
& +\left[\sum_{d=\left[L C L_{1}\right]+1}^{\left[L C L_{2}\right]}\left(\begin{array}{l}
n \\
d
\end{array}\right) p_{1}^{d}\left(1-p_{1}\right)^{n-d}+\sum_{d=\left[U C L_{2}\right]+1}^{\left[U C L_{1}\right]}\left(\begin{array}{l}
n \\
d
\end{array}\right) p_{1}^{d}\left(1-p_{1}\right)^{n-d}\right] \\
& \times\left[\sum_{d=\left[L C L_{2}\right]+1}^{\left[U C L_{2}\right]}\left(\begin{array}{l}
n \\
d
\end{array}\right) p_{1}^{d}\left(1-p_{1}\right)^{n-d}\right]^{i}
\end{aligned}
$$

Likewise, the probability when the shape parameter is shifted is specified as

$$
\begin{aligned}
\frac{P_{i n}^{2}}{p_{2}}= & \sum_{d=\left[L C L_{2}\right]+1}^{\left[U C L_{2}\right]}\left(\begin{array}{l}
n \\
d
\end{array}\right) p_{2}^{d}\left(1-p_{2}\right)^{n-d} \\
& +\left[\sum_{d=\left[L C L_{1}\right]+1}^{\left[L C L_{2}\right]}\left(\begin{array}{l}
n \\
d
\end{array}\right) p_{2}^{d}\left(1-p_{2}\right)^{(n-d)}+\sum_{d=\left[U C L_{2}\right]+1}^{\left[U C L_{1}\right]}\left(\begin{array}{l}
n \\
d
\end{array}\right) p_{2}^{d}\left(1-p_{2}\right)^{n-d}\right] \\
& \times\left[\sum_{d=\left[L C L_{2}\right]+1}^{\left[U C L_{2}\right]}\left(\begin{array}{l}
n \\
d
\end{array}\right) p_{2}^{d}\left(1-p_{2}\right)^{n-d}\right]^{i}
\end{aligned}
$$

Likewise, the probability when both shape and scale parameters are shifted is

$$
\begin{aligned}
\frac{P_{i n}^{3}}{p_{3}}= & \sum_{d=\left[L C L_{2}\right]+1}^{\left[U C L_{2}\right]}\left(\begin{array}{l}
n \\
d
\end{array}\right) p_{3}^{d}\left(1-p_{3}\right)^{n-d} \\
& +\left[\sum_{d=\left[L C L_{2}\right]+1}^{\left[L C L_{2}\right]}\left(\begin{array}{l}
n \\
d
\end{array}\right) p_{3}^{d}\left(1-p_{3}\right)^{n-d}+\sum_{d=\left[U C L_{2}\right]+1}^{\left[U C L_{1}\right]}\left(\begin{array}{l}
n \\
d
\end{array}\right) p_{3}^{d}\left(1-p_{3}\right)^{n-d}\right] \\
& \times\left[\sum_{d=\left[L C L_{2}\right]+1}^{\left[U C L_{2}\right]}\left(\begin{array}{l}
n \\
d
\end{array}\right) p_{3}^{d}\left(1-p_{3}\right)^{n-d}\right]^{i}
\end{aligned}
$$

The average run length $(A R L)$ is used to evaluate the efficiency of a control chart. The in-control $A R L$ and out of control $A R L$ are given in equations (24), (25), (26), and (27), respectively.

$$
\begin{aligned}
& A R L_{0}=\frac{1}{1-P_{i n}^{0}} \\
& A R L_{1}=\frac{1}{1-P_{i n}^{1}}
\end{aligned}
$$




$$
\begin{aligned}
& A R L_{2}=\frac{1}{1-P_{i n}^{2}} \\
& A R L_{3}=\frac{1}{1-P_{i n}^{3}}
\end{aligned}
$$

\subsection{Contrast of the proposed control chart}

Tables A14-A16 show the $A R L$ values for $n=30, A R L_{0}=200,300$, and 370 with $i=1,2,3$ for shift in the scale parameter.

Tables A17 and A18 show the $A R L$ values for $n=30, A R L_{0}=300$, and 370 with $i=1,2,3$ for shift in shape parameter, and for both shift parameters, respectively. It can be concluded from these tables that the $A R L$ values decrease as the shift size decreases $(c=1$ to 0.1$)$.

The proposed MDS control chart based on EHLD is compared with the existing control chart presented by Aslam [11] at $A R L_{0}=300,370, i=1$ and $n=30$, and the results are shown in Table A19. It can be seen that when $c=0.99, \alpha=1$ and $A R L_{0}=300$, the $A R L$ value of the proposed control chart is 100.42 , while it is 280.62 from the existing control chart. So, the proposed control is more responsive to identify a shift in the process as compared to the existing control chart.

The proposed control chart is also compared with the one proposed by Rao [6] at $A R L_{0}=200,300,370, i=1,2,3$, and results are shown in Table A20. It can be seen that for $c=0.9, \alpha=1$ and $A R L_{0}=200$, the $A R L$ value of the proposed control chart is 16.51, while it is 64.48 from the previous control chart. So, the proposed control is preferable in earlier detection of shifts.

\section{Algorithm}

Step 1. Set the values of $\alpha_{0}$ (shape parameter), $a$ (test termination ratio), and $r_{0}$ (in control target $A R L)$.

Step 2. Set the values of $n, k_{1}, k_{2}$.

Step 3. Put the values of $a, \alpha_{0}$ in equation (16) to find the failure probability $\left(p_{0}\right)$.

Step 4. Discover the control limits of the proposed control chart, using the values of $n, p_{0}, k_{1}$ and $k_{2}$ in equations (4a)-(4d).

Step 5. The probability that the process is stated in-control if the process is actually in control, by replacing the values of $p_{0}$ and control limits in equations (18), and also use equation (24) to locate $A R L_{0}$.

Step 6. Check parameters $n, k_{1}$, and $k_{2}$ such that the in-control $A R L_{0}$ is as near as to the final value $r_{0}$. 
Step 7. Continue Steps 4-6 for various combinations of $n, k_{1}$, and $k_{2}$ until you get an $A R L_{0}$ as near as to $r_{0}$.

Step 8. Replace the values $n, k_{1}$, and $k_{2}$ in equations (17)-(23), (25)-(27) for discovering the out of control $A R L_{1}$ for various shift values.

\subsection{Illustrative example}

We consider Hinkley's [20] real dataset. This dataset for Saint Paul, Minneapolis, is 30 consecutive rainfall values (in inches) in March over a period of 30 years. The observed values are: $0.77,1.74,0.81,1.20,1.95,1.20,0.47,1.43,3.37,2.20,3.00,3.09$, $1.51,2.10,0.52,1.62,1.31,0.32,0.59,0.81,2.81,1.87,1.18,1.35,4.75,2.48,0.96$, $1.89,0.90,2.05$.

Seo et al. [21], Azimi and Sarikhanbaglu [22], Torabi and Bagheri [23], Seo and Kang [15], and others evaluated this dataset. The exponentiated half logistic distribution suits the information well [15]. Here, $n=30, \alpha=2, i=1, a=0.32$, and $r_{0}=370$. The value of $p_{0}$ from equation (16) becomes 0.075 . The value of $\mu$ from equation (3) is calculated as 1.7627 with test duration $t_{0}=a \mu_{0}=0.32 \times 1.7627=0.564$. The control limits under MDS calculated are $U C L_{1}=3.15, U C L_{2}=2.64 L C L_{1}=0.21, L C L_{2}=0.72$ for the parameters $k_{1}=1.17, k_{2}=0.76$.

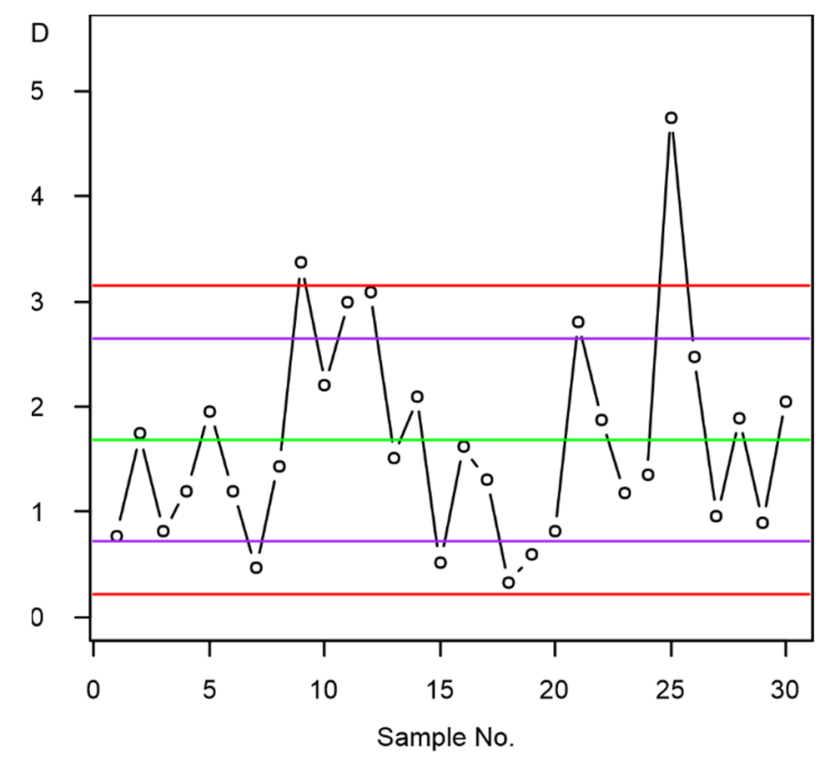

Fig. 3. The proposed MDS control chart for a real dataset

It can be seen from Fig. 3 that out of control signal is generated twice, while some points fall in the repetitive region. 


\subsection{Simulation study}

In this study, using simulated information, we address the implementation of the proposed control chart. The data is produced from an exponential half logistic distribution when $\alpha=3$ and $\sigma=1$. Let $n=30, a=0.88$, and $r_{0}=370$. The process is declared to be in-control when $\alpha=3$ and $\sigma=1$. The value of $p_{0}$ from equation (16) is calculated as $0.4092, \mu=2.16$, the test duration is therefore calculated as $t_{0}=a \mu_{0}=0.88 \times 2.16=1.90$. The value of $\bar{d}=\sum d_{i} / l=12.275$ and $l=40$. We find out the control limits coefficients $k_{1}=2.735302$, and $k_{2}=2.324929$, and control limits are $U C L_{1}=19.64, U C L_{2}=18.54, L C L_{1}=4.91$, $L C L_{2}=6.01$, the number of failures per subgroup is reported before the specified time. If the number of fail items in the subgroup is $7-18$, the process is said to be in-control. The sampling will be repeated if the subgroup includes 5, 6 or 19 failed items. If the number of failures is less than or equal to 4 , the process is stated to be out of control (Fig. 4). By comparing Figs. 4 and 5, we can conclude that the proposed control chart has the ability to detect a small shift in the process earlier than the existing control chart.

Table 2. The simulated data

\begin{tabular}{|c|c|c|c|c|c|c|c|c|c|c|c|c|c|c|c|c|c|c|c|c|}
\hline Subgroup & 1 & 2 & 3 & 4 & 5 & 6 & 7 & 8 & 9 & 10 & 11 & 12 & 13 & 14 & 15 & 16 & 17 & 18 & 19 & 20 \\
\hline$D$ & 11 & 11 & 15 & 11 & 13 & 13 & 9 & 11 & 16 & 14 & 14 & 13 & 17 & 19 & 16 & 8 & 16 & 15 & 11 & 11 \\
\hline Subgroup & 21 & 22 & 23 & 24 & 25 & 26 & 27 & 28 & 29 & 30 & 31 & 32 & 33 & 34 & 35 & 36 & 37 & 38 & 39 & 40 \\
\hline$D$ & 13 & 12 & 11 & 13 & 12 & 10 & 6 & 13 & 10 & 12 & 11 & 15 & 11 & 10 & 15 & 7 & 11 & 14 & 12 & 11 \\
\hline
\end{tabular}



Fig. 4. The proposed MDS control chart for simulated data 


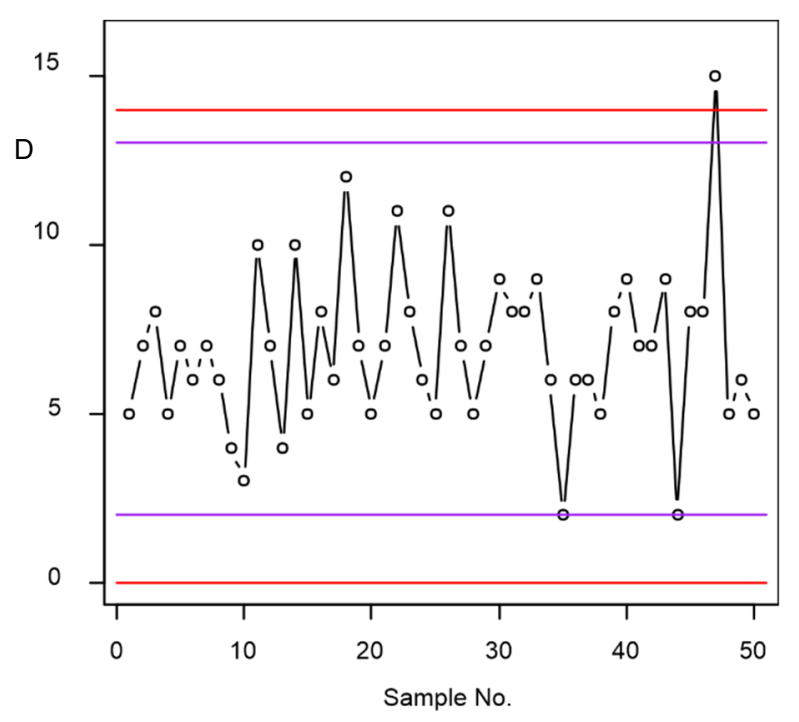

Fig. 5. Aslam's [11] chart for simulated data

\section{Conclusion}

We propose an attribute np control chart under RGS and MDS based on time truncated life tests for EHLD. The performance of the proposed control chart is evaluated in terms of $A R L$. The optimal parameters used for constructing the chart are determined such that the in-control $A R L$ is as close as to the specified value of $A R L$. The performance of the proposed chart is compared with the performance of the chart developed by Jeyadurga et al. [12]. The control chart performance in RGS is also contrasted with the control chart presented by Rao [6], based on EHLD. Results are presented in the form of tables, using different scales and shape parameters. These tables show that the proposed chart identifies the change quicker than the existing chart. The efficiency of the proposed MDS control chart is compared to the control chart results by Aslam [11]. The results indicate that the proposed control chart is more responsive than the existing one to recognize a shift in the process. The efficiency of the proposed MDS control chart is also compared to Rao's [6] results and concluded in the form of tables using different $A R L_{0}$ values. It is concluded that the proposed control is more responsive to identify a shift in the process as compared to the existing control chart. For future work, the proposed control chart might be applied to other distributions.

\section{Acknowledgements}

The authors are deeply thankful to the Editor and the Reviewers for their valuable suggestions that had led to improve the quality of this manuscript. 


\section{References}

[1] Sherman R.E., Design and evaluation of a RGS plan, Technometrics, 1965, 7, 11-21.

[2] Balamurali S., Jun C.-H., Repetitive group sampling procedure for variables inspection, J. Appl. Stat., 2006, 33, 327-338.

[3] Ahmad L., Aslam M., Jun C.-H., Designing of X-bar control charts based on process capability index using repetitive sampling, Trans. Inst. Measure. Control, 2014, 36, 367-374.

[4] Aslam M., AZAm M., Jun C.-H., New attributes and variables control charts under repetitive sampling, Ind. Eng. Manage. Syst., 2014, 13, 101-106.

[5] Aslam M., Khan N., AZAm M., Jun C.-H., Designing of a new monitoring t-chart using repetitive sampling, Inf. Sci., 2014, 269, 210-216.

[6] RAO G., A control chart for time truncated life tests using exponentiated half logistic distribution, Appl. Math. Inf. Sci., 2018, 12, 125-131.

[7] WORTHAM A., BAKER R., Multiple deferred state sampling inspection, Int. J. Prod. Res., 1976, 14, 719-731.

[8] Aslam M., Yen C.-H., Chang C.-H., Jun C.-H., Multiple dependent state variable sampling plans with process loss consideration, Int. J. Adv. Manuf. Techn., 2014, 71, 1337-1343.

[9] Aslam M., Khan N., JUN C.-H., A multiple dependent state control chart based on double control limits, Res. J. Appl. Sci. Eng. Techn., 2014, 7, 4490-4493.

[10] RAO G.S., NAIDU C., Acceptance sampling plans for percentiles based on the exponentiated half logistic distribution, Appl. Appl. Math., 2014, 9, 39-53.

[11] Aslam M., Time truncated attribute control chart for the Weibull distribution using MDS, Comm. Stat.-Sim. Comp., 2019, 48, 1219-1228.

[12] Jeyadurga P., Balamurali S., Aslam M., Design of an attribute np control chart for process monitoring based on repetitive group sampling under truncated life tests, Comm. Stat.-Theory Meth., 2018, 47, 5934-5955.

[13] MudholKar G.S., SRIVASTAVA D.K., Exponentiated Weibull family for analyzing bathtub failure-rate data, IEEE Trans. Rel., 1993, 42, 299-302.

[14] Cordeiro G.M., AlizAdeh M., OrTEGa E.M., The exponentiated half-logistic family of distributions: Properties and applications, J. Prob. Stat., 2014, 2014.

[15] Seo J.-I., KANG S.-B., Notes on the exponentiated half logistic distribution, Appl. Math. Model., 2015, $39,6491-6500$.

[16] Elgarhy M., Haq M., Ozel G., A new exponentiated extended family of distributions with applications, Gazi University J. Sci., 2017, 30, 101-115.

[17] USMAn R.M., HAQ M., TALIB J., Kumaraswamy half-logistic distribution: properties and applications, J. Stat. Appl. Prob., 2017, 6, 597-609.

[18] Anwar M., BiBI A., The half-logistic generalized Weibull distribution, J. Prob. Stat., 2018, 2018.

[19] MONTGOMERY D.C., Introduction to statistical quality control, Wiley, 2007.

[20] Hinkley D., On quick choice of power transformation, J. Royal Stat. Soc., Series C, 1977, 26, 67-69.

[21] SEO J.-I., LEE H.-J., KAN S.-B., Estimation for generalized half logistic distribution based on records, J. Korean Data Inf. Sci. Soc., 2012, 23, 1249-1257.

[22] Azimi R., SARIKHANBAglu F.A., Bayes and empirical bayes estimators based on generalized half logistic records data, Journal of Statistics Appl. Prob., 2014, 3, 145 ?.

[23] TORABI H., BAGHERI F., Estimation of parameters for an extended generalized halflogistic distribution based on complete and censored data, J. Iranian Stat. Soc., 2010, 9, 171-195. 


\section{Appendix}

Table A1. ARLs while shape parameter is shifted for specified sample sizes as $r_{0}=200$

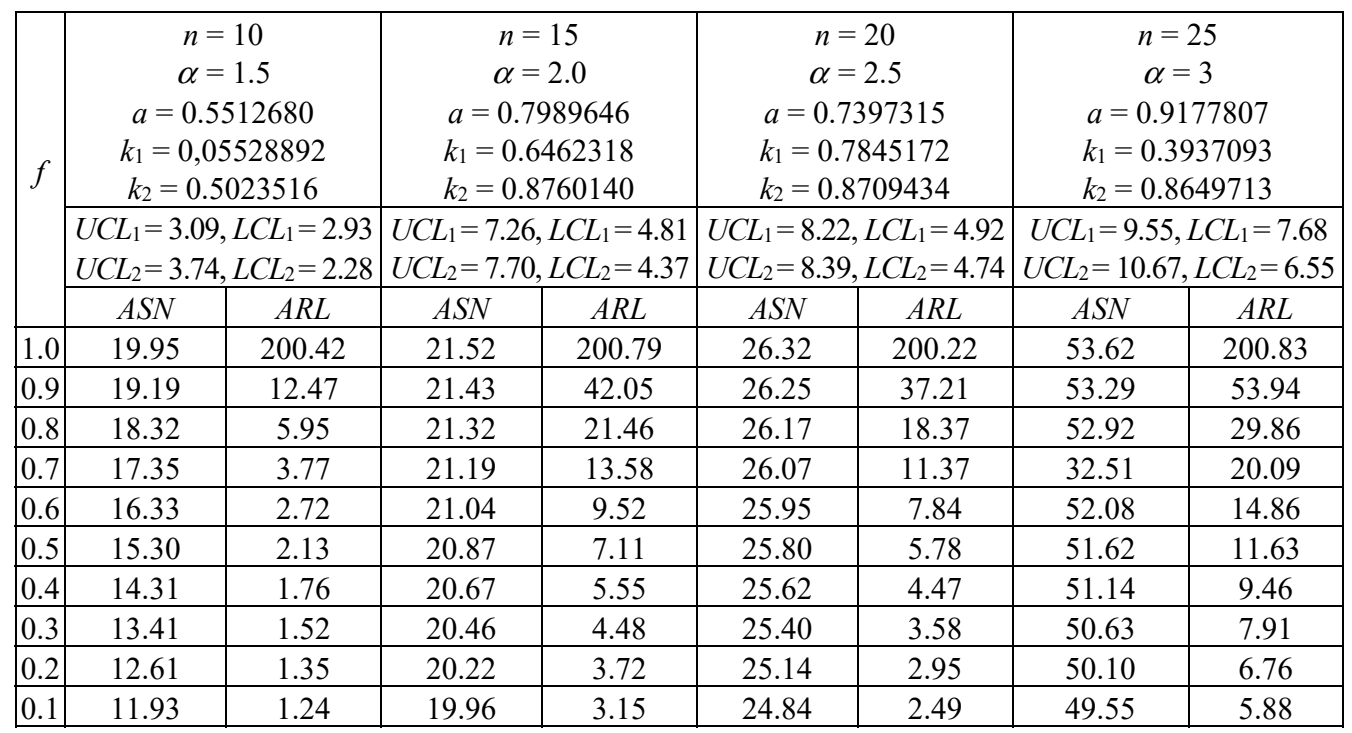

Table A2. ARLs while the shape parameter is shifted for specified sample sizes as $r_{0}=300$ and $\alpha=2$

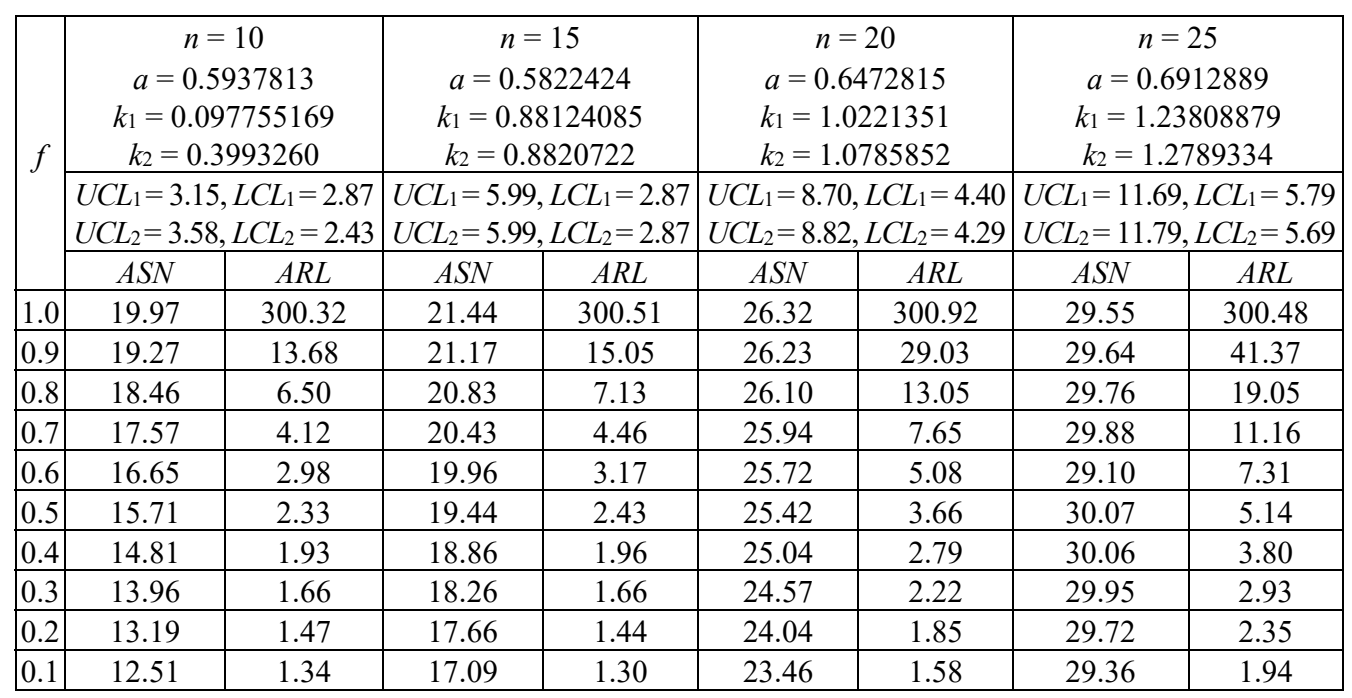


Table A3. ARLs while shape parameter is shifted for specified sample sizes as $r_{0}=370$ and $\alpha=2$

\begin{tabular}{|c|c|c|c|c|c|c|c|c|}
\hline \multirow[t]{3}{*}{$f$} & \multicolumn{2}{|c|}{$\begin{array}{c}n=10 \\
a=0.9424639 \\
k_{1}=0.52002428 \\
k_{2}=0.559912\end{array}$} & \multicolumn{2}{|c|}{$\begin{array}{c}n=15 \\
a=0.7967768 \\
k_{1}=0.71566975 \\
k_{2}=0.9685180\end{array}$} & \multicolumn{2}{|c|}{$\begin{array}{c}n=20 \\
a=0.6466634 \\
k_{1}=0.9532185 \\
k_{2}=1.048110\end{array}$} & \multicolumn{2}{|c|}{$\begin{array}{c}n=25 \\
a=0.7581569 \\
k_{1}=1.2570453 \\
k_{2}=1.3277907\end{array}$} \\
\hline & $\begin{array}{l}U C L_{1}=5 \\
U C L_{2}=5\end{array}$ & $\begin{array}{l}L C L_{1}=3.90 \\
L C L_{2}=3.84\end{array}$ & $\begin{array}{l}U C L_{1}= \\
U C L_{2}=\end{array}$ & $\begin{array}{l}L C L_{1}=4.66 \\
L C L_{2}=4.18\end{array}$ & $\begin{array}{l}U C L_{1}=8 \\
U C L_{2}=8\end{array}$ & $\begin{array}{l}L C L_{1}=4.55 \\
L C L_{2}=4.35\end{array}$ & $\begin{array}{l}U C L_{1}=1 \\
U C L_{2}=1\end{array}$ & $\begin{array}{l}L C L_{1}=6.51 \\
L C L_{2}=6.34\end{array}$ \\
\hline & $A S N$ & $A R L$ & $A S N$ & $A R L$ & $A S N$ & $A R L$ & $A S N$ & $A R L$ \\
\hline 1.0 & 16.29 & 370.21 & 21.53 & 370.01 & 26.32 & 370.56 & 29.59 & 370.24 \\
\hline \begin{tabular}{|l|}
0.9 \\
\end{tabular} & 16.25 & 89.99 & 21.44 & 46.93 & 26.23 & 29.70 & 29.64 & 63.08 \\
\hline 0.8 & 16.19 & 49.86 & 21.33 & 22.72 & 26.11 & 13.20 & 29.71 & 29.64 \\
\hline \begin{tabular}{|l|}
0.7 \\
\end{tabular} & 16.15 & 33.86 & 21.21 & 14.07 & 25.94 & 7.71 & 29.79 & 17.50 \\
\hline 0.6 & 16.09 & 25.29 & 21.06 & 9.75 & 25.72 & 5.11 & 19.89 & 11.53 \\
\hline 0.5 & 16.03 & 19.99 & 20.88 & 7.23 & 25.43 & 3.67 & 29.98 & 8.11 \\
\hline \begin{tabular}{|l|}
0.4 \\
\end{tabular} & 15.97 & 16.42 & 20.68 & 5.61 & 25.05 & 2.79 & 30.05 & 5.99 \\
\hline 0.3 & 15.90 & 13.86 & 20.46 & 4.51 & 24.58 & 2.23 & 30.08 & 4.59 \\
\hline 0.2 & 15.84 & 11.95 & 20.22 & 3.73 & 24.05 & 1.85 & 30.05 & 3.63 \\
\hline 0.1 & 15.78 & 10.48 & 19.96 & 3.16 & 23.46 & 1.58 & 29.95 & 2.95 \\
\hline
\end{tabular}

Table A4. ARLs while shape parameter is shifted for specified sample sizes as $r 0=370$ and $\alpha=3$

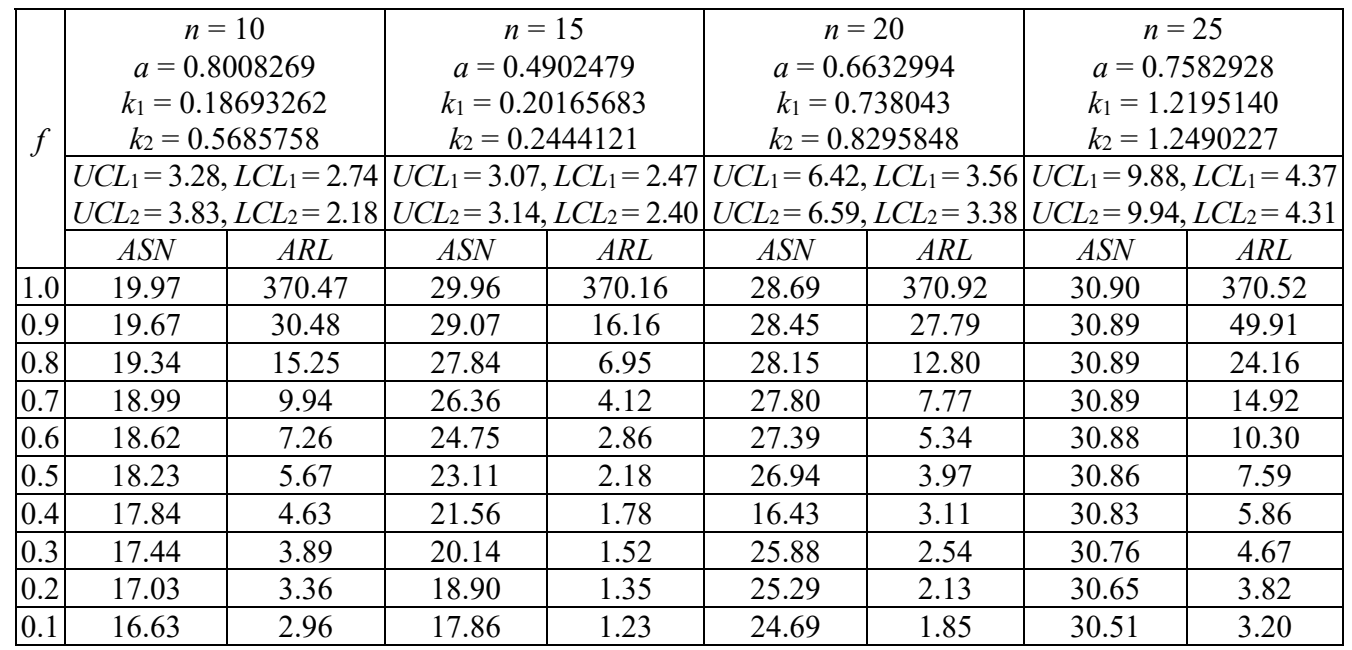


Table A5. ARLs while shape parameter is shifted for specified sample sizes as $r_{0}=300$ and $\alpha=3$

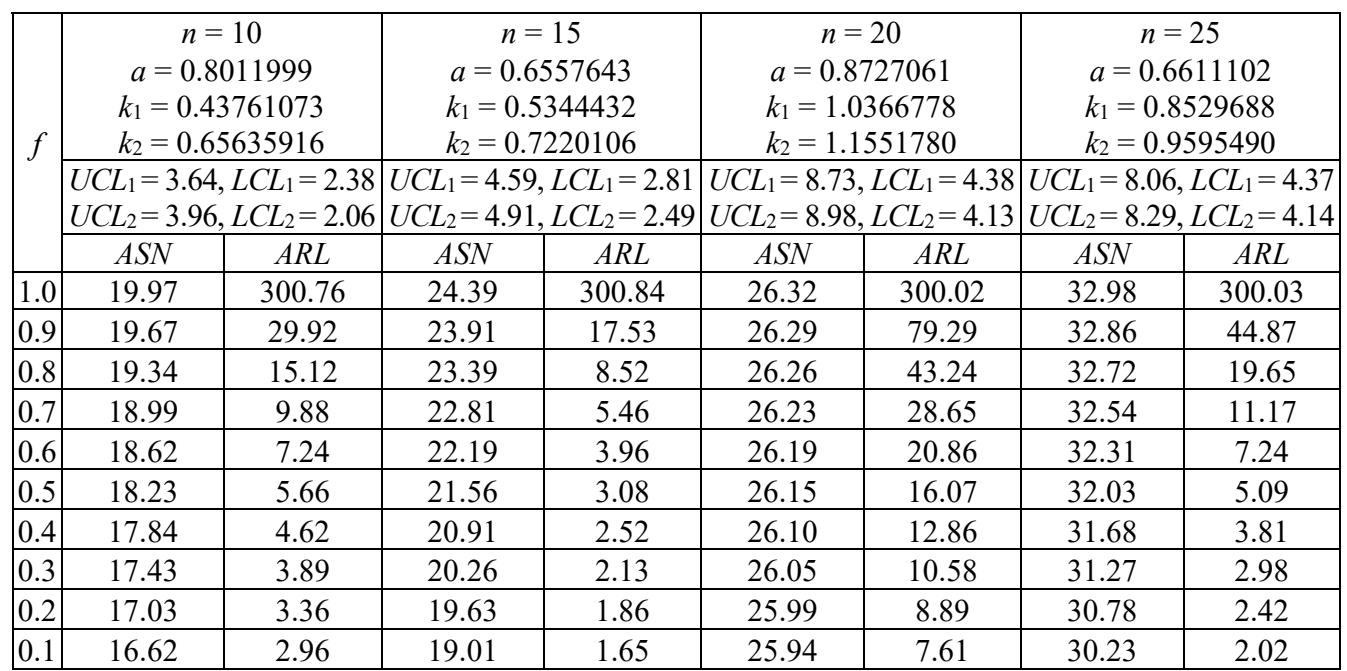

Table A6. ARLs while scale parameter is shifted for specified sample sizes as $r_{0}=200$

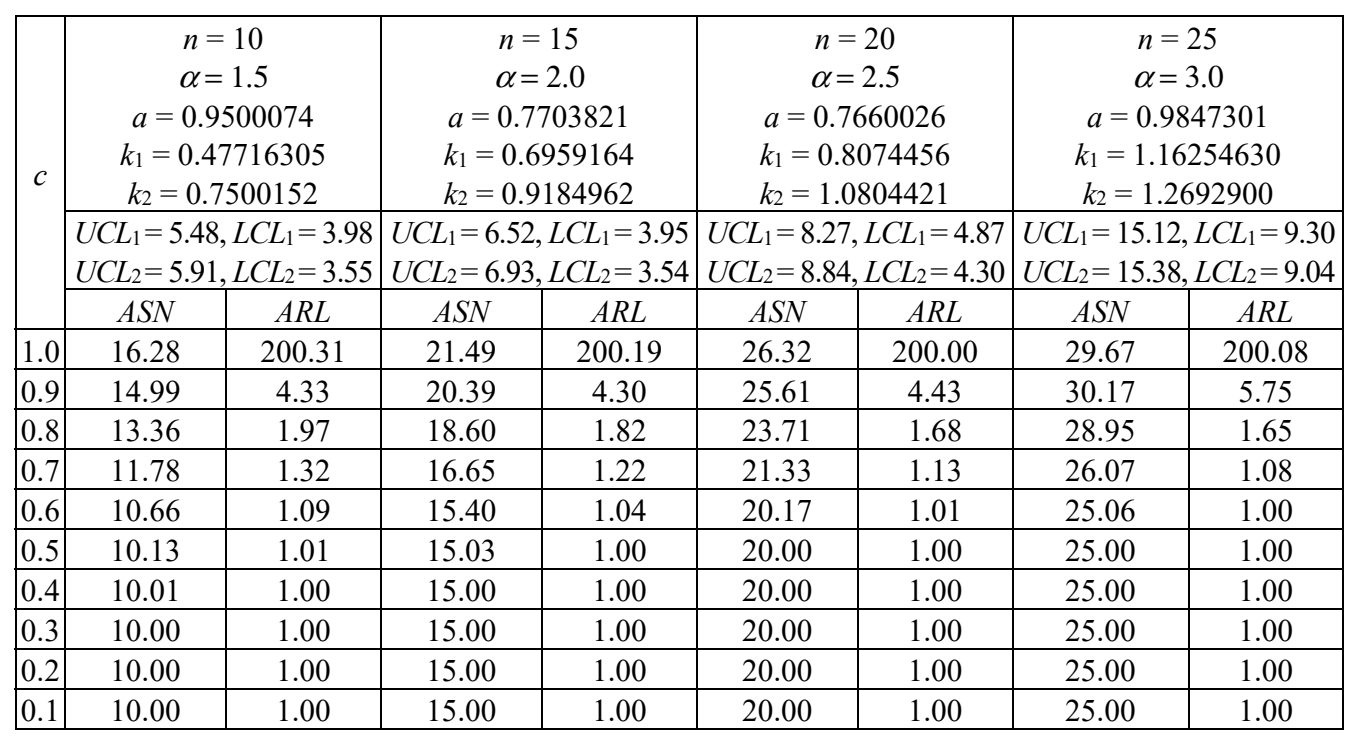


Table A7. ARLs while scale parameter is shifted for specified sample sizes as $r_{0}=300$



Table A8. ARLs while scale parameter is shifted for specified sample sizes as $r_{0}=370$

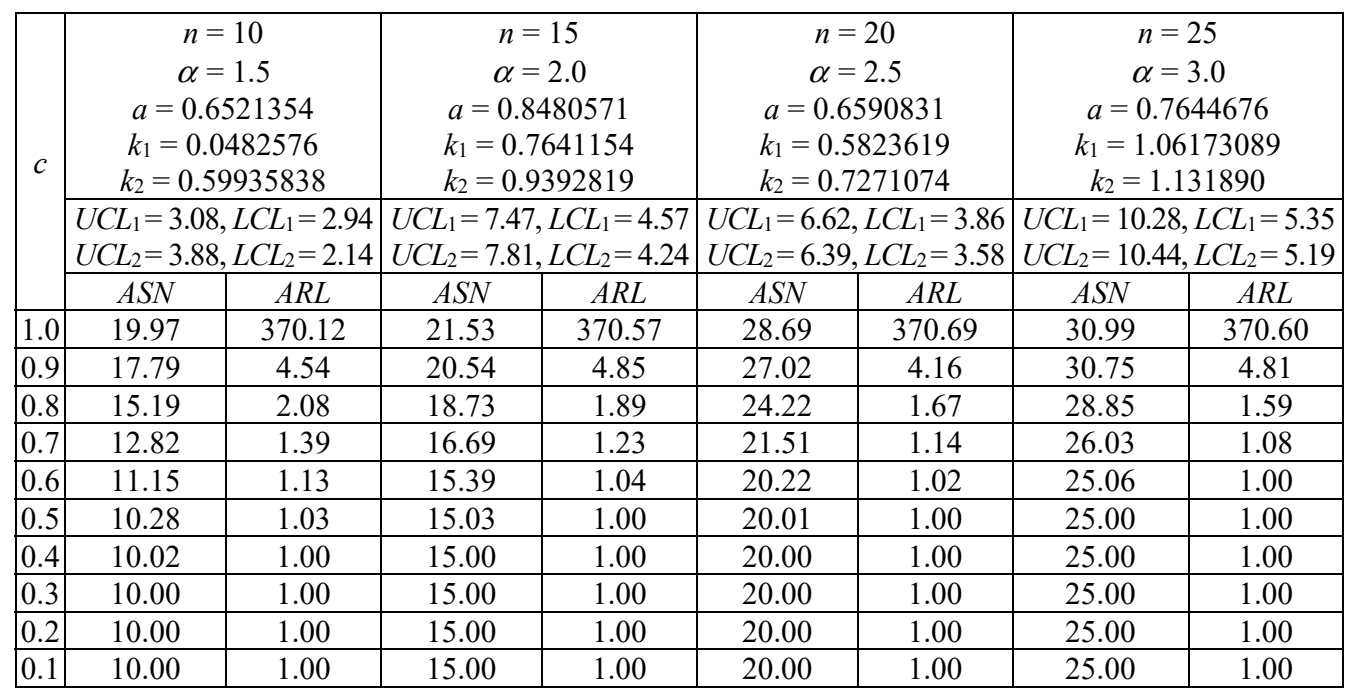


Table A9. ARLs while both shape and scale parameters are shifted for specified sample sizes as $r_{0}=200$

\begin{tabular}{|c|c|c|c|c|c|c|c|c|c|}
\hline \multirow{3}{*}{$c$} & \multirow{3}{*}{$f$} & \multicolumn{2}{|c|}{$\begin{array}{c}n=10 \\
\alpha=1.5 \\
a=0.3186226 \\
k_{1}=0.4739333 \\
k_{2}=0.6542452\end{array}$} & \multicolumn{2}{|c|}{$\begin{array}{c}n=15 \\
\alpha=2.0 \\
a=0.4129923 \\
k_{1}=0.7344990 \\
k_{2}=0.8054793\end{array}$} & \multicolumn{2}{|c|}{$\begin{array}{c}n=20 \\
\alpha=2.5 \\
a=0.95929883 \\
k_{1}=0.607698 \\
k_{2}=8363810\end{array}$} & \multicolumn{2}{|c|}{$\begin{array}{c}n=25 \\
\alpha=3.0 \\
a=0.9702668 \\
k_{1}=0.9089739 \\
k_{2}=0.9865484\end{array}$} \\
\hline & & \multicolumn{2}{|c|}{$\begin{array}{l}U C L_{1}=5.48 \\
L C L_{1}=3.98 \\
U C L_{2}=5.76 \\
L C L_{2}=3.69\end{array}$} & \multicolumn{2}{|c|}{$\begin{array}{l}U C L_{1}=8.28 \\
L C L_{1}=5.45 \\
U C L_{2}=8.42 \\
L C L_{2}=5.31\end{array}$} & \multicolumn{2}{|c|}{$\begin{array}{c}U C L_{1}=10.15 \\
L C L_{1}=7.45 \\
U C L_{2}=10.66 \\
L C L_{2}=6.95\end{array}$} & \multicolumn{2}{|c|}{$\begin{array}{c}U C L_{1}=11.55 \\
L C L_{1}=7.15 \\
U C L_{2}=11.73 \\
L C L_{2}=6.96\end{array}$} \\
\hline & & $A S N$ & $A R L$ & $A S N$ & $A R L$ & $A S N$ & $A R L$ & $A S N$ & $A R L$ \\
\hline 1.0 & 0.1 & 16.28 & 200.01 & 21.54 & 200.12 & 31.64 & 200.14 & 35.72 & 200.00 \\
\hline 0.9 & 0.9 & 13.36 & 1.91 & 18.27 & 1.61 & 29.99 & 9.62 & 34.22 & 9.88 \\
\hline 0.8 & 0.8 & 14.71 & 3.33 & 19.66 & 2.50 & 27.46 & 3.25 & 32.69 & 3.63 \\
\hline 0.7 & 0.7 & 16.07 & 17.18 & 20.86 & 5.95 & 25.34 & 1.96 & 30.80 & 2.19 \\
\hline 0.4 & 0.4 & 16.05 & 21.79 & 20.96 & 7.89 & 22.24 & 1.23 & 28.09 & 1,34 \\
\hline 0.3 & 0.3 & 14.72 & 3.58 & 20.06 & 3.31 & 22.26 & 1.23 & 28.14 & 1.23 \\
\hline 0.2 & 0.2 & 13.65 & 2.17 & 19.37 & 2.34 & 22.99 & 1.35 & 28.89 & 1.50 \\
\hline 0.1 & & 13.32 & 1.95 & 19.42 & 2.39 & 25.14 & 1.89 & 30.82 & 2.20 \\
\hline
\end{tabular}

Table A10. ARLs of the proposed control chart with the existing control chart while shape parameter is shifted as $r_{0}=300$ and $\alpha=2$

\begin{tabular}{|c|c|c|c|c|c|c|c|c|}
\hline \multirow[b]{2}{*}{$f$} & Proposed & Existing & Proposed & Existing & Proposed & Existing & Proposed & Existing \\
\hline & \multicolumn{2}{|c|}{$\begin{array}{c}a=0.582424 \\
n=15 \\
k_{1}=0.88124085 \\
k_{2}=0.8820722\end{array}$} & \multicolumn{2}{|c|}{$\begin{array}{c}a=0.3389691 \\
n=15 \\
k_{1}=1.369041 \\
k_{2}=2.790004\end{array}$} & \multicolumn{2}{|c|}{$\begin{array}{c}a=6912889 \\
n=25 \\
k_{1}=1.23808879 \\
k_{2}=1.2789334\end{array}$} & \multicolumn{2}{|c|}{$\begin{array}{c}a=0.618004 \\
n=25 \\
k_{1}=1.872718 \\
k_{2}=2.695981\end{array}$} \\
\hline & \multicolumn{2}{|c|}{$\begin{array}{l}U C L_{1}=5.99, L C L_{1}=2.87 \\
U C L_{2}=5.99, L C L_{2}=2.87\end{array}$} & \multicolumn{2}{|c|}{$\begin{array}{c}U C L_{1}=9, L C L_{1}=3 \\
U C L_{2}=12, L C L_{2}=1\end{array}$} & \multicolumn{2}{|c|}{$\begin{array}{l}U C L_{1}=11.69, L C L_{1}=5.79 \\
U C L_{2}=11.79, L C L_{2}=5.69\end{array}$} & \multicolumn{2}{|c|}{$\begin{array}{c}U C L_{1}=20, L C L_{1}=10 \\
U C L_{2}=22, L C L_{2}=8\end{array}$} \\
\hline & $A S N$ & $A R L$ & $A S N$ & $A R L$ & $A S N$ & $A R L$ & $A S N$ & $A R L$ \\
\hline 1.0 & 21.44 & 300.51 & 16.92 & 302.19 & 29.55 & 300.48 & 25.88 & 300.01 \\
\hline 0.9 & 21.17 & 15.05 & 19.95 & 190.22 & 29.64 & 41.37 & 26.35 & 116.59 \\
\hline 0.8 & 20.83 & 7.12 & 17.47 & 94.14 & 29.76 & 19.05 & 27.72 & 37.70 \\
\hline 0.7 & 20.43 & 4.46 & 18.62 & 43.09 & 29.88 & 11.16 & 30.37 & 12.56 \\
\hline 0.6 & 19.96 & 3.17 & 20.70 & 19.02 & 29.10 & 7.31 & 34.19 & 4.57 \\
\hline 0.5 & 19.44 & 2.43 & 23.98 & 8.19 & 30.07 & 5.14 & 26.69 & 2.01 \\
\hline 0.4 & 18.86 & 1.96 & 28.21 & 3.57 & 30.06 & 3.80 & 33.90 & 1.24 \\
\hline 0.3 & 18.26 & 1.66 & 30.54 & 1.76 & 29.95 & 2.93 & 28.45 & 1.04 \\
\hline 0.2 & 17.66 & 1.44 & 26.29 & 1.15 & 29.72 & 2.35 & 25.50 & 1.00 \\
\hline 0.1 & 17.09 & 1.30 & 18.73 & 1.01 & 29.36 & 1.94 & 25.01 & 1.00 \\
\hline
\end{tabular}


Table A11. ARLs of the proposed control chart with the existing control chart while shape parameter is shifted as $r_{0}=370$ and $\alpha=3$

\begin{tabular}{|c|c|c|c|c|c|c|c|c|}
\hline \multirow[b]{2}{*}{$f$} & Proposed & Existing & Proposed & Existing & Proposed & Existing & Proposed & Existing \\
\hline & $\begin{aligned} a & =0 . \\
n & \\
k_{1} & =0.2 \\
k_{2} & =0 .\end{aligned}$ & $\begin{array}{l}2479 \\
55683 \\
4121 \\
\end{array}$ & $\begin{array}{r}a=1 . \\
n= \\
k_{1}=1 . \\
k_{2}=3\end{array}$ & $\begin{array}{l}9771 \\
5 \\
0701 \\
315 \\
\end{array}$ & $\begin{array}{c}a=0 \\
n \\
k_{1}= \\
k_{2}=0\end{array}$ & $\begin{aligned} a= & 0.6632994 \\
& n=20\end{aligned}$ & \multicolumn{2}{|c|}{$\begin{array}{c}a=0.5122036 \\
n=20\end{array}$} \\
\hline & \multicolumn{2}{|c|}{$\begin{array}{l}U C L_{1}=3.07, L C L_{1}=2.47 \\
U C L_{2}=3.14, L C L_{2}=2.40\end{array}$} & \multicolumn{2}{|c|}{$\begin{array}{l}U C L_{1}=14, L C L_{1}=7 \\
U C L_{2}=16, L C L_{2}=5\end{array}$} & \multicolumn{2}{|c|}{$\begin{array}{l}U C L_{1}=6.42, L C L_{1}=3.56 \\
U C L_{2}=6.59, L C L_{2}=3.38\end{array}$} & \\
\hline & $A S N$ & $A R L$ & $A S N$ & $A R L$ & $A S N$ & $A R L$ & $A S N$ & $A R L$ \\
\hline 1.0 & 29.96 & 370.16 & 15.68 & 370.06 & 28.69 & 370.92 & 20.81 & 370.01 \\
\hline 0.9 & 29.07 & 16.16 & 16.20 & 130.42 & 28.45 & 27.79 & 21.06 & 223.80 \\
\hline 0.8 & 27.84 & 6.95 & 17.23 & 46.69 & 28.15 & 12.80 & 21.82 & 92.05 \\
\hline 0.7 & 26.36 & 4.12 & 19.03 & 17.00 & 27.80 & 7.77 & 23.33 & 35.32 \\
\hline 0.6 & 24.75 & 2.86 & 21.74 & 6.43 & 27.39 & 5.34 & 25.97 & 13.51 \\
\hline 0.5 & 23.11 & 2.18 & 24.41 & 2.70 & 26.94 & 3.97 & 29.87 & 5.30 \\
\hline 0.4 & 21.56 & 1.78 & 24.10 & 1.46 & 26.43 & 3.11 & 33.38 & 2.31 \\
\hline 0.3 & 20.14 & 1.52 & 20.06 & 1.09 & 25.88 & 2.54 & 31.85 & 1.32 \\
\hline 0.2 & 18.90 & 1.35 & 16.37 & 1.00 & 25.29 & 2.13 & 25.41 & 1.05 \\
\hline 0.1 & 17.86 & 1.23 & 15.07 & 1.00 & 24.69 & 1.85 & 20.79 & 1.00 \\
\hline
\end{tabular}

Table A12. ARLs of the proposed control chart with the existing control chart while shape parameter is shifted as $r_{0}=370$ and $\alpha=2$

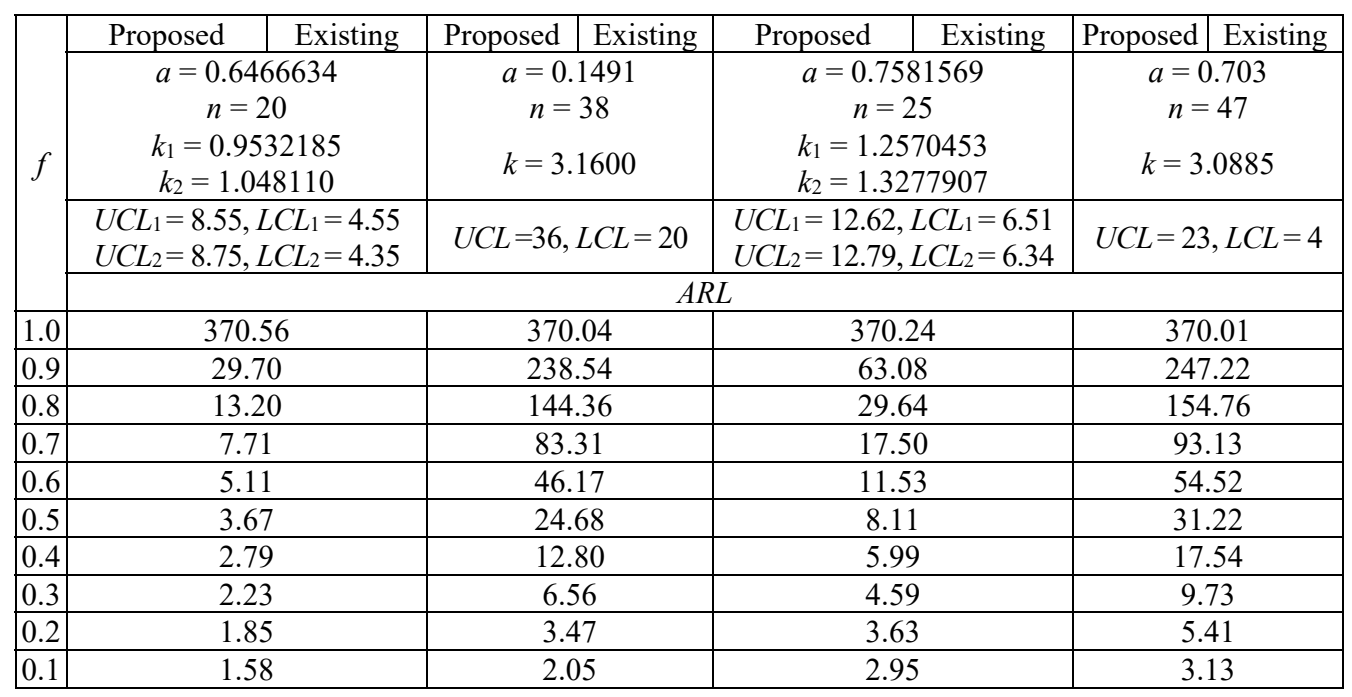


Table A13. ARLs of the proposed control chart with the existing control chart while scale parameter is shifted as $r_{0}=370$

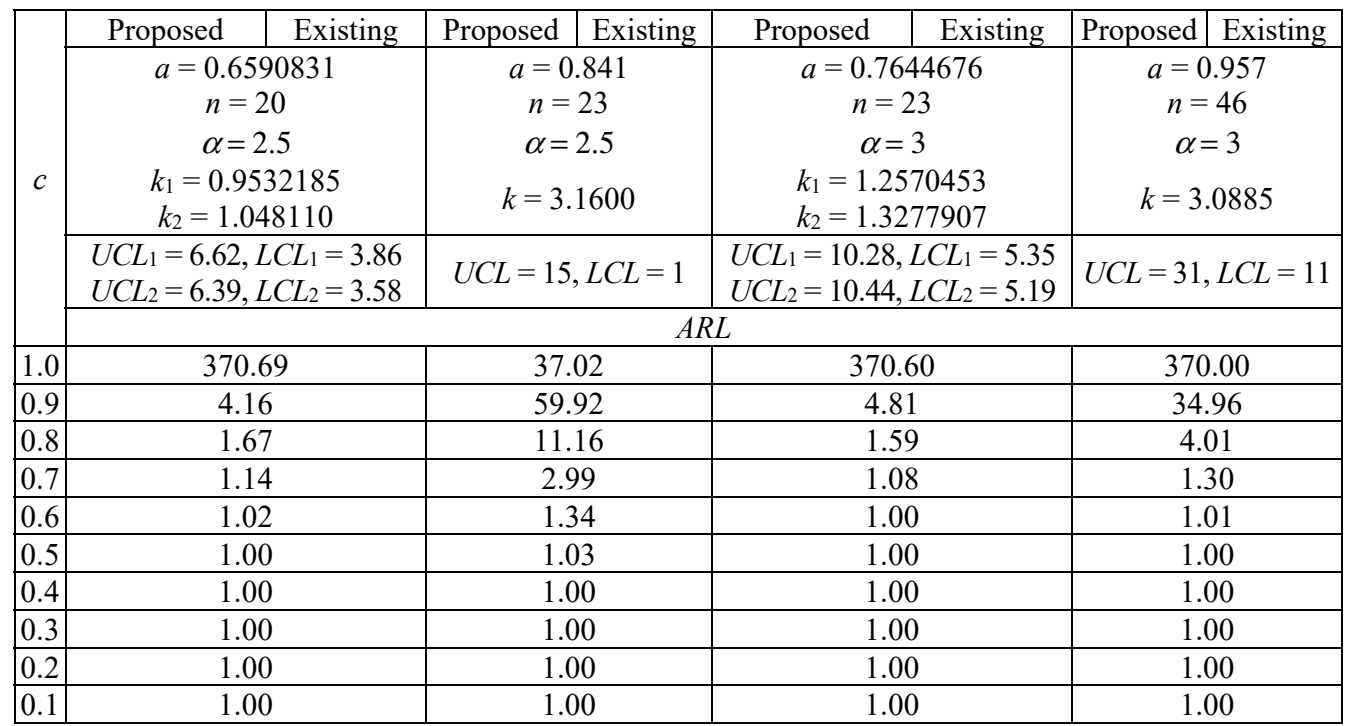

Table A14. ARL values of the proposed control chart for the shifted scale parameter as $A R L_{0}=200$ and $n=30$

\begin{tabular}{|c|c|c|c|c|c|c|c|c|c|c|}
\hline$i$ & \multicolumn{9}{|c|}{1} & \multicolumn{9}{|c|}{2} & \multicolumn{3}{c|}{3} \\
\hline$k_{1}$ & 1.21 & 3.83 & 3.91 & 3.13 & 1.72 & 2.87 & 3.24 & 3.44 & 2.81 \\
\hline$k_{2}$ & 1.15 & 3.49 & 2.94 & 2.91 & 1.55 & 2.42 & 2.73 & 2.75 & 2.35 \\
\hline$\alpha$ & 1 & 2 & 3 & 1 & 2 & 3 & 1 & 2 & 3 \\
\hline$a$ & 0.35 & 0.27 & 0.72 & 0.29 & 0.73 & 0.96 & 0.21 & 0.96 & 0.87 \\
\hline$c$ & \multicolumn{9}{|c|}{$A R L$} \\
\hline 1 & 200.17 & 200.04 & 200.05 & 200.01 & 200.03 & 200.07 & 200.01 & 200.05 & 200.02 \\
\hline 0.99 & 114.62 & 182.13 & 152.94 & 185.17 & 96.87 & 124.76 & 187.19 & 151.90 & 128.95 \\
\hline 0.95 & 36.50 & 124.64 & 59.90 & 135.48 & 23.40 & 40.02 & 142.99 & 63.27 & 42.76 \\
\hline 0.93 & 25.48 & 102.85 & 39.09 & 115.61 & 14.85 & 26.13 & 124.68 & 43.35 & 28.01 \\
\hline 0.91 & 18.88 & 84.75 & 5.99 & 98.50 & 10.11 & 17.71 & 108.52 & 30.33 & 18.99 \\
\hline 0.9 & 16.51 & 76.89 & 21.33 & 90.87 & 8.50 & 14.73 & 101.18 & 25.54 & 15.79 \\
\hline 0.88 & 12.92 & 63.22 & 14.58 & 77.24 & 6.20 & 10.37 & 87.84 & 18.33 & 11.09 \\
\hline 0.85 & 9.34 & 47.03 & 8.55 & 60.37 & 4.11 & 6.40 & 70.83 & 11.52 & 6.81 \\
\hline 0.8 & 5.90 & 28.59 & 3.97 & 39.75 & 2.39 & 3.23 & 49.06 & 5.86 & 3.39 \\
\hline 0.75 & 3.99 & 17.33 & 2.21 & 25.98 & 1.63 & 1.92 & 33.63 & 3.39 & 1.98 \\
\hline 0.7 & 2.85 & 10.54 & 1.51 & 16.88 & 1.27 & 1.35 & 22.83 & 2.19 & 1.37 \\
\hline 0.6 & 1.67 & 4.06 & 1.07 & 7.10 & 1.03 & 1.02 & 10.26 & 1.20 & 1.03 \\
\hline 0.5 & 1.19 & 1.82 & 1.00 & 3.10 & 1.00 & 1.00 & 4.57 & 1.01 & 1.00 \\
\hline 0.4 & 1.02 & 1.12 & 1.00 & 1.56 & 1.00 & 1.00 & 2.14 & 1.00 & 1.00 \\
\hline 0.3 & 1.00 & 1.00 & 1.00 & 1.06 & 1.00 & 1.00 & 1.22 & 1.00 & 1.00 \\
\hline 0.2 & 1.00 & 1.00 & 1.00 & 1.00 & 1.00 & 1.00 & 1.00 & 1.00 & 1.00 \\
\hline 0.1 & 1.00 & 1.00 & 1.00 & 1.00 & 1.00 & 1.00 & 1.00 & 1.00 & 1.00 \\
\hline
\end{tabular}


Table A15. $A R L$ values of the proposed control chart for shifted scale parameter as $A R L_{0}=300$ and $n=30$

\begin{tabular}{|c|c|c|c|c|c|c|c|c|c|}
\hline$i$ & \multicolumn{3}{|c|}{1} & \multicolumn{3}{|c|}{2} & \multicolumn{3}{|c|}{3} \\
\hline$k_{1}$ & 3.38 & 3.09 & 2.74 & 1.19 & 2.73 & 2.78 & 3.38 & 2.69 & 3.60 \\
\hline$k_{2}$ & 0.12 & 2.82 & 2.21 & 1.18 & 2.45 & 2.39 & 2.95 & 2.28 & 3.09 \\
\hline$\alpha$ & 1 & 2 & 3 & 1 & 2 & 3 & 1 & 2 & 3 \\
\hline$a$ & 0.02 & 0.77 & 0.88 & 0.39 & 0.79 & 0.82 & 0.24 & 0.94 & 0.52 \\
\hline$c$ & & & & & $A R L$ & & & & \\
\hline 1 & 300.10 & 300.17 & 300.22 & 300.26 & 300.10 & 300.01 & 300.07 & 300.02 & 300.50 \\
\hline 0.99 & 100.42 & 221.96 & 133.85 & 146.68 & 192.57 & 175.88 & 278.81 & 177.36 & 250.52 \\
\hline 0.95 & 26.82 & 90.37 & 34.42 & 41.19 & 67.14 & 53.03 & 206.88 & 56.84 & 121.92 \\
\hline 0.93 & 19.43 & 62.16 & 22.29 & 28.26 & 45.69 & 34.22 & 177.72 & 38.20 & 85.54 \\
\hline 0.91 & 15.15 & 43.67 & 15.18 & 20.69 & 32.19 & 22.93 & 152.400 & 26.70 & 60.31 \\
\hline 0.9 & 13.62 & 36.81 & 12.69 & 17.99 & 27.24 & 18.96 & 141.03 & 22.54 & 50.75 \\
\hline 0.88 & 11.29 & 26.39 & 9.04 & 13.96 & 19.76 & 13.18 & 120.60 & 16.29 & 36.10 \\
\hline 0.85 & 8.93 & 16.38 & 5.69 & 9.97 & 12.52 & 7.96 & 95.05 & 10.32 & 21.97 \\
\hline 0.8 & 6.54 & 7.84 & 2.96 & 6.18 & 6.26 & 3.84 & 63.34 & 5.21 & 10.08 \\
\hline 0.75 & 5.08 & 4.11 & 1.81 & 4.11 & 3.43 & 2.16 & 41.74 & 2.92 & 5.00 \\
\hline 0.7 & 4.10 & 2.40 & 1.30 & 2.89 & 2.10 & 1.45 & 27.23 & 1.86 & 2.76 \\
\hline 0.6 & 2.88 & 1.22 & 1.01 & 1.68 & 1.17 & 1.03 & 11.32 & 1.12 & 1.27 \\
\hline 0.5 & 2.16 & 1.01 & 1.00 & 1.19 & 1.01 & 1.00 & 4.69 & 1.00 & 1.01 \\
\hline 0.4 & 1.68 & 1.00 & 1.00 & 1.03 & 1.00 & 1.00 & 2.09 & 1.00 & 1.00 \\
\hline 0.3 & 1.37 & 1.00 & 1.00 & 1.00 & 1.00 & 1.00 & 1.18 & 1.00 & 1.00 \\
\hline 0.2 & 1.15 & 1.00 & 1.00 & 1.00 & 1.00 & 1.00 & 1.00 & 1.00 & 1.00 \\
\hline 0.1 & 1.02 & 1.00 & 1.00 & 1.00 & 1.00 & 1.00 & 1.00 & 1.00 & 1.00 \\
\hline
\end{tabular}

Table A16. $A R L$ values of the proposed control chart for shifted scale parameter as $A R L_{0}=370$ and $n=30$

\begin{tabular}{|c|c|c|c|c|c|c|c|c|c|}
\hline$i$ & \multicolumn{3}{|c|}{1} & \multicolumn{3}{|c|}{2} & \multicolumn{3}{|c|}{3} \\
\hline$k_{1}$ & 2.95 & 1.48 & 3.83 & 1.56 & 3.95 & 3.78 & 2.57 & 3.26 & 2.73 \\
\hline$k_{2}$ & 2.43 & 1.32 & 2.86 & 1.51 & 3.02 & 3.49 & 2.10 & 2.61 & 2.32 \\
\hline$\alpha$ & 1 & 2 & 3 & 1 & 2 & 3 & 1 & 2 & 3 \\
\hline$a$ & 0.69 & 0.84 & 0.71 & 0.92 & 0.87 & 0.39 & 0.51 & 0.77 & 0.88 \\
\hline$c$ & & & & & $A R L$ & & & & \\
\hline 1 & 370.37 & 370.26 & 370.28 & 370.03 & 370.13 & 370.05 & 370.01 & 370.16 & 370.14 \\
\hline 0.99 & 262.69 & 92.25 & 264.98 & 208.03 & 278.90 & 318.39 & 192.94 & 261.80 & 148.44 \\
\hline 0.95 & 111.27 & 17.17 & 94.12 & 55.05 & 110.81 & 174.32 & 61.81 & 100.37 & 36.14 \\
\hline 0.93 & 81.88 & 10.84 & 60.28 & 35.11 & 73.65 & 129.01 & 44.44 & 68.35 & 23.28 \\
\hline 0.91 & 62.34 & 7.46 & 39.50 & 23.89 & 49.79 & 95.54 & 33.84 & 47.71 & 15.81 \\
\hline 0.9 & 54.85 & 6.32 & 32.20 & 20.06 & 41.15 & 82.25 & 29.94 & 40.11 & 13.19 \\
\hline 0.88 & 42.95 & 4.69 & 21.70 & 14.52 & 28.39 & 61.03 & 23.90 & 28.63 & 9.38 \\
\hline 0.85 & 30.32 & 3.22 & 12.44 & 9.42 & 16.72 & 39.17 & 17.61 & 17.64 & 5.88 \\
\hline 0.8 & 17.45 & 1.98 & 5.50 & 5.09 & 7.54 & 19.02 & 11.13 & 8.35 & 3.03 \\
\hline 0.75 & 10.29 & 1.42 & 2.87 & 3.09 & 3.91 & 9.56 & 7.28 & 4.32 & 1.83 \\
\hline 0.7 & 6.21 & 1.16 & 1.79 & 2.07 & 2.38 & 5.06 & 4.87 & 2.49 & 1.32 \\
\hline 0.6 & 2.55 & 1.01 & 1.10 & 1.25 & 1.31 & 1.83 & 2.37 & 1.24 & 1.02 \\
\hline 0.5 & 1.35 & 1.00 & 1.00 & 1.03 & 1.02 & 1.10 & 1.38 & 1.01 & 1.00 \\
\hline 0.4 & 1.03 & 1.00 & 1.00 & 1.00 & 1.00 & 1.00 & 1.05 & 1.00 & 1.00 \\
\hline 0.3 & 1.00 & 1.00 & 1.00 & 1.00 & 1.00 & 1.00 & 1.00 & 1.00 & 1.00 \\
\hline 0.2 & 1.00 & 1.00 & 1.00 & 1.00 & 1.00 & 1.00 & 1.00 & 1.00 & 1.00 \\
\hline 0.1 & 1.00 & 1.00 & 1.00 & 1.00 & 1.00 & 1.00 & 1.00 & 1.00 & 1.00 \\
\hline
\end{tabular}


Table A17. $A R L$ values of the proposed control chart for shifted shape parameter as $A R L_{0}=300$ and $n=30$

\begin{tabular}{|c|c|c|c|c|c|c|c|c|c|}
\hline$i$ & \multicolumn{3}{|c|}{1} & \multicolumn{3}{c|}{2} & \multicolumn{3}{c|}{3} \\
\hline$k_{1}$ & 3.86 & 2.72 & 3.46 & 3.48 & 2.85 & 3.29 & 1.52 & 1.36 & 3.53 \\
\hline$k_{2}$ & 2.98 & 2.30 & 2.93 & 2.68 & 2.47 & 2.93 & 1.51 & 1.31 & 2.49 \\
\hline$\alpha$ & 1 & 2 & 3 & 1 & 2 & 3 & 1 & 2 & 3 \\
\hline$a$ & 0.82 & 0.79 & 0.97 & 0.95 & 0.44 & 0.83 & 0.43 & 0.23 & 0.94 \\
\hline$f$ & \multicolumn{9}{|c|}{$A R L$} \\
\hline 1 & 300.14 & 300.07 & 300.01 & 300.07 & 300.00 & 300.05 & 300.03 & 300.05 & 300.36 \\
\hline 0.99 & 292.91 & 275.64 & 298.38 & 295.73 & 242.27 & 293.41 & 178.81 & 90.14 & 292.73 \\
\hline 0.95 & 265.98 & 206.08 & 292.00 & 279.21 & 131.88 & 268.44 & 62.63 & 21.60 & 265.46 \\
\hline 0.93 & 253.60 & 182.05 & 288.88 & 271.42 & 105.11 & 256.87 & 45.39 & 15.04 & 253.50 \\
\hline 0.91 & 241.87 & 162.48 & 285.79 & 263.93 & 86.11 & 245.85 & 34.80 & 11.31 & 242.47 \\
\hline 0.9 & 236.23 & 154.00 & 284.27 & 260.29 & 78.53 & 240.53 & 30.92 & 10.00 & 237.28 \\
\hline 0.88 & 225.38 & 139.10 & 281.24 & 253.21 & 66.06 & 230.28 & 24.93 & 8.03 & 227.47 \\
\hline 0.85 & 210.09 & 120.78 & 276.79 & 243.05 & 52.08 & 215.80 & 18.79 & 6.07 & 214.05 \\
\hline 0.8 & 186.96 & 97.68 & 269.56 & 227.26 & 36.38 & 193.83 & 12.60 & 4.18 & 194.59 \\
\hline 0.75 & 166.38 & 80.66 & 262.58 & 212.75 & 26.17 & 174.27 & 8.96 & 3.11 & 178.05 \\
\hline 0.7 & 147.99 & 67.58 & 255.83 & 199.35 & 19.19 & 156.82 & 6.64 & 2.44 & 163.83 \\
\hline 0.6 & 116.69 & 48.87 & 243.04 & 175.44 & 10.77 & 127.34 & 4.00 & 1.70 & 140.64 \\
\hline 0.5 & 91.41 & 36.26 & 231.12 & 154.73 & 6.36 & 103.76 & 2.66 & 1.33 & 122.58 \\
\hline 0.4 & 71.01 & 27.36 & 220.03 & 136.70 & 3.98 & 84.84 & 1.93 & 1.14 & 108.14 \\
\hline 0.3 & 54.76 & 20.92 & 209.69 & 121.02 & 2.65 & 69.60 & 1.51 & 1.05 & 96.32 \\
\hline 0.2 & 42.09 & 16.18 & 200.04 & 107.52 & 1.90 & 57.30 & 1.26 & 1.01 & 86.48 \\
\hline 0.1 & 32.44 & 12.65 & 191.01 & 96.09 & 1.46 & 47.33 & 1.12 & 1.00 & 78.15 \\
\hline
\end{tabular}

Table A18. $A R L$ values of the proposed control chart for shifted scale and shape parameters as $A R L_{0}=370$ and $n=30$

\begin{tabular}{|c|c|c|c|c|c|c|c|c|c|c|}
\hline \multirow{2}{*}{\multicolumn{2}{|c|}{$\frac{i}{k_{1}}$}} & \multicolumn{3}{|c|}{1} & \multicolumn{3}{|c|}{2} & \multicolumn{3}{|c|}{3} \\
\hline & & 3.93 & 3.13 & 3.36 & 3.00 & 3.95 & 3.28 & 2.68 & 3.81 & 3.15 \\
\hline \multicolumn{2}{|c|}{$k_{2}$} & 2.93 & 2.68 & 3.02 & 2.51 & 2.97 & 2.89 & 2.12 & 2.91 & 2.75 \\
\hline \multicolumn{2}{|c|}{$\alpha$} & 1 & 2 & 3 & 1 & 2 & 3 & 1 & 2 & 3 \\
\hline \multicolumn{2}{|c|}{$a$} & 0.67 & 0.56 & 0.74 & 0.73 & 0.70 & 0.75 & 0.44 & 0.77 & 0.93 \\
\hline$c$ & $f$ & \multicolumn{9}{|c|}{$A R L$} \\
\hline 1 & 1.0 & 370.01 & 370.11 & 370.01 & 370.00 & 370.08 & 370.12 & 370.08 & 370.28 & 370.59 \\
\hline 0.9 & 0.2 & 11.70 & 4.08 & 25.24 & 15.00 & 11.09 & 24.56 & 1.75 & 19.07 & 35.78 \\
\hline 0.8 & 0.3 & 10.95 & 4.44 & 21.89 & 12.88 & 10.05 & 21.03 & 1.98 & 15.46 & 59.83 \\
\hline 0.7 & 0.4 & 7.78 & 3.97 & 14.69 & 8.39 & 7.01 & 13.95 & 2.01 & 9.41 & 28.13 \\
\hline 0.6 & 0.5 & 4.32 & 2.86 & 7.54 & 4.29 & 3.87 & 7.12 & 1.79 & 4.52 & 10.03 \\
\hline 0.5 & 0.6 & 2.15 & 1.75 & 3.13 & 2.00 & 1.92 & 2.97 & 1.42 & 1.97 & 3.01 \\
\hline 0.4 & 0.7 & 1.24 & 1.12 & 1.34 & 1.15 & 1.08 & 1.31 & 1.12 & 1.05 & 1.17 \\
\hline 0.3 & 0.8 & 1.00 & 1.00 & 1.00 & 1.00 & 1.00 & 1.00 & 1.01 & 1.00 & 1.00 \\
\hline 0.2 & 0.9 & 1.00 & 1.00 & 1.00 & 1.00 & 1.00 & 1.00 & 1.00 & 1.00 & 1.00 \\
\hline 0.1 & 1.0 & 1.00 & 1.00 & 1.00 & 1.00 & 1.00 & 1.00 & 1.00 & 1.00 & 1.00 \\
\hline
\end{tabular}


Table A19. Comparison in ARLs of the proposed control chart and the existing chart at $A R L_{0}=300,370, i=1$, and $n=30$

\begin{tabular}{|c|c|c|c|c|c|c|c|c|c|c|c|c|}
\hline \multirow{3}{*}{\begin{tabular}{|c|}
$A R L_{0}$ \\
$\alpha$ \\
$c$ \\
\end{tabular}} & \multicolumn{6}{|c|}{300} & \multicolumn{6}{|c|}{370} \\
\hline & \multicolumn{2}{|c|}{1} & \multicolumn{2}{|c|}{2} & \multicolumn{2}{|c|}{3} & \multicolumn{2}{|c|}{1} & \multicolumn{2}{|c|}{-} & \multicolumn{2}{|c|}{3} \\
\hline & Pro & Exi & Pro & Exi & Pro & Exi & Pro & Exi & Pro & Exi & Pro & Exi \\
\hline 1 & 300.10 & 300.12 & 300.17 & 300.36 & 300.22 & 300.03 & 370.37 & 370.0 & 370.26 & 370.0 & 370.28 & 370.03 \\
\hline 0.99 & 100.42 & 280.62 & 221.96 & 255.62 & 133.85 & 243.42 & 262.69 & 351.75 & 92.25 & 326.03 & 264.98 & 322.11 \\
\hline 0.95 & 26.82 & 204.05 & 90.37 & 131.96 & 34.42 & 88.14 & 111.27 & 260.99 & 17.17 & 166.03 & 94.12 & 158.25 \\
\hline 0.93 & 19.43 & 170.13 & 62.16 & 94.21 & 22.29 & 51.12 & 81.88 & 214.54 & 10.84 & 112.28 & 60.28 & 106.07 \\
\hline 0.91 & 15.15 & 140.41 & 43.67 & 67.13 & 15.18 & 29.75 & 62.34 & 172.37 & 7.46 & 74.90 & 39.50 & 70.40 \\
\hline 0.9 & 13.62 & 127.17 & 36.81 & 56.65 & 12.96 & 22.80 & 54.85 & 153.46 & 6.32 & 61.04 & 32.20 & 57.27 \\
\hline 0.88 & 11.29 & 103.85 & 26.39 & 40.37 & 9.04 & 13.62 & 42.95 & 120.34 & 4.69 & 40.52 & 21.70 & 37.91 \\
\hline 0.85 & 8.93 & 75.97 & 16.34 & 24.40 & 5.69 & 6.67 & 30.32 & 81.96 & 3.22 & 22.10 & 12.44 & 20.56 \\
\hline 0.8 & 6.54 & 44.50 & 7.84 & 10.86 & 2.96 & 2.54 & 17.45 & 42.06 & 1.98 & 8.52 & 5.50 & 7.80 \\
\hline 0.75 & 5.08 & 25.84 & 4.11 & & & 1.39 & 10.29 & 21.46 & 1.42 & 3.73 & 2.87 & 3.35 \\
\hline 0.7 & 4.10 & 14.99 & 2.40 & 2.75 & 1.30 & 1.07 & 6.21 & 11.16 & 1.16 & 1.97 & 1.79 & 1.77 \\
\hline 0.6 & 2.88 & 5.22 & 1.22 & 1.24 & 1.01 & 1.00 & 2.55 & 3.49 & 1.01 & 1.08 & 1.10 & 1.04 \\
\hline 0.5 & 2.16 & 2.12 & 1.01 & 1.01 & 1.00 & 1.00 & 1.35 & 1.53 & 1.00 & 1.00 & 1.00 & 1.00 \\
\hline 0.4 & 1.68 & 1.20 & 1.00 & 1.00 & 1.00 & 1.00 & 1.03 & 1.06 & 1.00 & 1.00 & 1.00 & 1.00 \\
\hline 0.3 & 1.37 & 1.01 & 1.00 & 1.00 & 1.00 & 1.00 & 1.00 & 1.00 & 1.00 & 1.00 & 1.00 & 1.00 \\
\hline 0.2 & 1.15 & 1.00 & 1.00 & 1.00 & 1.00 & 1.00 & 1.00 & 1.00 & 1.00 & 1.00 & 1.00 & 1.00 \\
\hline 0.1 & 1.02 & 1.00 & 1.00 & 1.00 & 1.00 & 1.00 & 1.00 & 1.00 & 1.00 & 1.00 & 1.00 & 1.00 \\
\hline
\end{tabular}

Pro - stands for the proposed control charts, Exi - stands for the existing control chart.

Table A20. Comparison in ARLs of the proposed control chart and the existing chart (single sampling plan) at $A R L_{0}=200,300,370$

\begin{tabular}{|c|c|c|c|c|c|c|c|c|c|c|c|c|}
\hline & \multicolumn{4}{|c|}{$A R L_{0}=200, i=1$} & \multicolumn{4}{c|}{$A R L_{0}=300, i=2$} & \multicolumn{3}{c|}{$A R L_{0}=370, i=3$} \\
\hline$\alpha$ & \multicolumn{2}{|c|}{1} & \multicolumn{2}{|c|}{3} & \multicolumn{3}{c|}{1} & \multicolumn{3}{|c|}{3} & \multicolumn{3}{|c|}{2} & \multicolumn{3}{|c|}{3} \\
\hline$c$ & Pro & Exi & Pro & Exi & Pro & Exi & Pro & Exi & Pro & Exi & Pro & Exi \\
\hline 1 & 200.17 & 200.01 & 200.05 & 200.00 & 300.26 & 300.00 & 300.01 & 300.00 & 370.16 & 370.00 & 370.14 & 370.00 \\
\hline 0.9 & 16.51 & 64.48 & 21.33 & 23.28 & 17.99 & 175.23 & 18.96 & 21.66 & 40.11 & 60.94 & 13.19 & 34.96 \\
\hline 0.8 & 5.90 & 15.02 & 3.97 & 3.16 & 6.18 & 45.01 & 3.84 & 2.92 & 8.35 & 11.01 & 3.03 & 4.01 \\
\hline 0.7 & 2.85 & 4.21 & 1.51 & 1.21 & 2.89 & 11.51 & 1.45 & 1.16 & 2.49 & 2.87 & 1.32 & 1.30 \\
\hline 0.6 & 1.67 & 1.68 & 1.07 & 1.00 & 1.68 & 3.51 & 1.03 & 1.00 & 1.24 & 1.29 & 1.02 & 1.0 \\
\hline 0.5 & 1.19 & 1.08 & 1.00 & 1.00 & 1.19 & 1.50 & 1.00 & 1.00 & 1.01 & 1.01 & 1.00 & 1.00 \\
\hline 0.4 & 1.02 & 1.00 & 1.00 & 1.00 & 1.03 & 1.04 & 1.00 & 1.00 & 1.00 & 1.00 & 1.00 & 1.00 \\
\hline 0.3 & 1.00 & 1.00 & 1.00 & 1.00 & 1.00 & 1.00 & 1.00 & 1.00 & 1.00 & 1.00 & 1.00 & 1.00 \\
\hline 0.2 & 1.00 & 1.00 & 1.00 & 1.00 & 1.00 & 1.00 & 1.00 & 1.00 & 1.00 & 1.00 & 1.00 & 1.00 \\
\hline 0.1 & 1.00 & 1.00 & 1.00 & 1.00 & 1.00 & 1.00 & 1.00 & 1.00 & 1.00 & 1.00 & 1.00 & 1.00 \\
\hline
\end{tabular}

Pro - stands for the proposed control charts, Exi - stands for the existing control chart. 